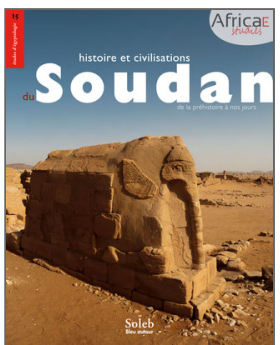

Olivier Cabon (dir.)

Histoire et civilisation du Soudan

De la préhistoire à nos jours

\title{
4. Les fils royaux de Koush
}

Colonisation égyptienne. 1 450-850 av. J.-C.

\section{Claude Rilly}

DOI : 10.4000/books.africae.2802

Éditeur: Africae, Soleb, Bleu autour

Lieu d'édition : Paris, Khartoum

Année d'édition : 2017

Date de mise en ligne : 17 janvier 2022

Collection : Africae Studies

EAN électronique : 9782493207074

\section{OpenEdition}

\author{
Books
}

http://books.openedition.org

\section{Référence électronique}

RILLY, Claude. 4. Les fils royaux de Koush : Colonisation égyptienne. $1450-850$ av. J.-C In : Histoire et civilisation du Soudan : De la préhistoire à nos jours [en ligne]. Paris, Khartoum : Africae, 2017 (généré le 28 janvier 2022). Disponible sur Internet : <http://books.openedition.org/africae/2802>. ISBN : 9782493207074. DOI : https://doi.org/10.4000/books.africae.2802. 


\title{
les fils royaux de Koush
}

\author{
colonisation égyptienne
}

1450-850 av. J.-C. 


\section{de la colonisation égyptienne à la fin de Méroé}

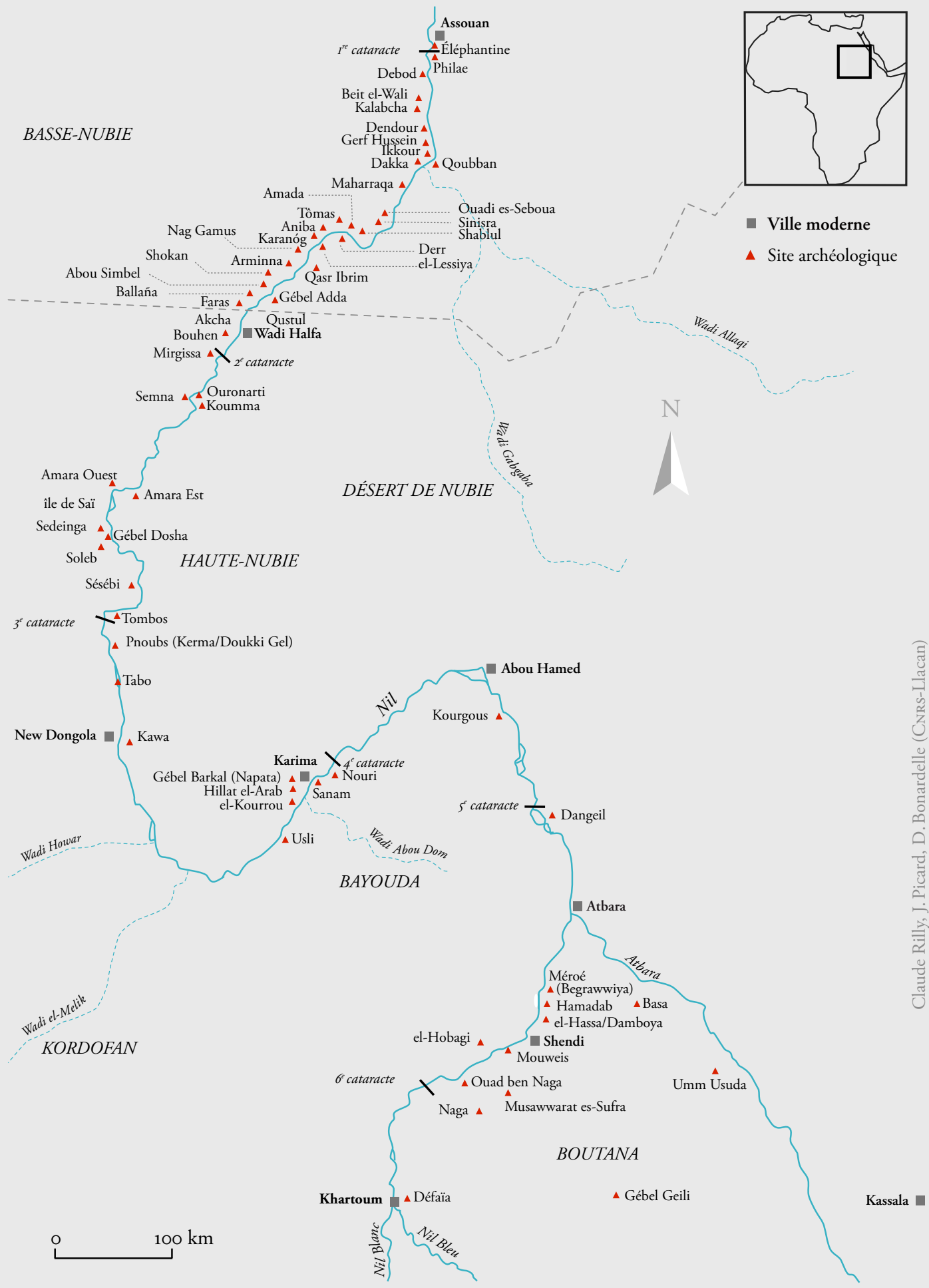


Pour près de six cents ans, le nord du Soudan actuel allait être intégré dans l'Empire des pharaons. À la tête de cette rentable colonie, ils nommèrent des administrateurs appelés «fils royaux de Koush». Mais la mainmise sur la Nubie ne fut pas chose aisée. La reconquête égyptienne des territoires perdus à la fin du Moyen Empire entre la première et la deuxième cataracte avait déjà commencé au temps de Kamosé, le dernier roi de la XVII dynastie basée à Thèbes (vers 1550 av. J.-C.). Toutefois, la grande affaire de son règne et du suivant fut de chasser d'Égypte les rois hyksôs qui depuis plus d'un siècle occupaient le nord du pays. Son père, Séqénenrê Taâ, était d'ailleurs mort sur le champ de bataille face aux armées de ces «Asiatiques». Sur sa momie aux traits convulsés visible au musée du Caire, le crâne est entaillé par la marque nette d'une hache de guerre. Une tablette présente Kamosé se plaignant d'être "installé entre un Noir et un Asiatique, chacun ayant sa portion de l'Égypte, qu'ils partagent avec moi ». Un autre texte d'une stèle de Karnak décrit comment les soldats de Kamosé interceptèrent sur la route des oasis un messager envoyé par le roi hyksôs Apopi au nouveau souverain de Kerma. Il était porteur d'une dépêche où Apopi enjoignait le roi de Koush d'attaquer Kamosé au sud, tandis qu'il le tiendrait occupé au nord.

\section{La conquête du royaume de Kerma les premières victoires égyptiennes}

Peut-être le pharaon thébain saisit-il l'opportunité de la succession en cours à Kerma pour annexer les marches septentrionales du royaume. Une inscription de Bouhen, en Basse-Nubie, commémore la construction d'une forteresse nouvelle. Durant le règne de son successeur Ahmosis, premier roi de la XVIII dynastie, la domination égyptienne progresse vers le sud: c'est désormais l'île de Saï, lieu stratégique le plus important de Moyenne-Nubie, qui est contrôlée par les armées de Pharaon. Les étapes de la conquête - et, en filigrane, les revers de cette politique d'expansion — sont relatées, bien que sommairement, dans les stèles officielles commémorant les victoires égyptiennes, ainsi que dans les autobiographies des officiers qui ont participé à ces campagnes.

Le plus complet de ces récits privés est l'autobiographie que nous a laissée Ahmosé, fils d'Abana, gravée sur les murs de sa tombe d'el-Kab (voir encadré p. 89 sq.). Cette cité, l'antique Nekheb, avait eu maille à partir peu auparavant avec les armées de Koush, puisqu'elle avait subi l'assaut d'une coalition rassemblée par le roi de Kerma contre le royaume thébain (voir chapitre précédent, p. 59 sq.). Cet épisode douloureux explique sans doute l'esprit de revanche qui caractérise le récit d'Ahmosé, ainsi que les noms avilissants donnés à ses esclaves ramenés du royaume kermaïte, dont la liste 
le Soudan

\section{8}

des origines

à la chute

du sultanat

Fung suit la narration. De façon inattendue dans la société patrilinéaire qu'est l'Égypte ancienne, Ahmosé est désigné par le nom de sa mère, Abana, comme d'ailleurs son père cité plus loin dans le texte, Baba, fils de Raïnet. Ce dernier n'était qu'un simple soldat servant à la fin de la XVII ${ }^{\mathrm{e}}$ dynastie. Le récit de son fils est donc celui d'une ascension sociale due à ses exploits militaires. L'époque se prêtait bien à de tels destins puisque, par la force de leurs armes, les pharaons du début du Nouvel Empire transformèrent un État-croupion autour de Thèbes en un Empire immense et puissant.

La carrière d'Ahmosé commence sous son homonyme le roi Ahmosis (la différence de transcription est purement conventionnelle), premier pharaon de la XVIII ${ }^{\mathrm{e}}$ dynastie et vainqueur des Hyksôs. Elle se termine sous le règne de Thoutmosis Ir, où l'officier, presque quinquagénaire, accomplit ses derniers exploits. Il vivra au moins jusqu'au règne de Thoutmosis II et s'éteindra, à plus de soixante-dix ans, comblé d'honneurs et de richesses.

Embarqué comme mousse dans la flotte de guerre égyptienne, il est ensuite affecté parmi les équipages qui accompagnent le roi Ahmosis dans la reconquête du nord de l'Égypte sur les Hyksôs, la prise d'Avaris, leur capitale, et la poursuite de leurs troupes fugitives jusqu'à Sharouhen, leur base arrière dans le pays de Canaan. Débarrassé de l'occupant hyksôs, Ahmosis tourne ensuite ses armes vers le royaume de Kerma. Il n'est pas question de pousser alors jusqu'à la capitale, encore moins de coloniser le pays, mais d'affaiblir un pouvoir qui fait peser une menace sur l'Égypte fraîchement réunifiée et de créer une large zone de sécurité jusqu'en amont de la deuxième cataracte.

La victoire d'Ahmosis ne mit pas un terme définitif au danger puisque, par deux fois, il lui fallut mater des agressions contre les territoires nouvellement conquis au sud. Nous ignorons qui sont Aata et Tétian. Le premier n'est désigné que par son nom, le second est décrit simplement comme un "ennemi", mais il est vraisemblable d'y voir des princes affiliés au pouvoir de Kerma. Dans toutes ces campagnes, Ahmosé, fils d'Abana, alors très jeune, montra sa bravoure. Il fut nommé «combattant du souverain", un titre suffisamment glorieux pour qu'il en fît le nouveau nom (Qen-en-pa-heqa) d'un des captifs qui lui avaient été donnés comme esclaves. Mais le meilleur était à venir pour lui. Vers l'an 9 de son règne, le nouveau pharaon, Amenhotep ${ }^{\mathrm{er}}$, reprit le combat contre Koush. Ahmosé, alors largement trentenaire, accompagna le roi dans cette nouvelle expédition, faisant preuve à la fois de ses talents de marinier et d'ardeur au combat. Ici encore, selon toute vraisemblance, Kerma n'avait pas été atteinte. Le chef d'armée, appelé simplement "archer nubien», fut capturé, mais rien n'indique qu'il s'agissait du roi lui-même. 


\section{Autobiographie d'Ahmosé, fils d'Abana}

Inscriptions de sa tombe à el-Kab, vers 1465 av. J.-C.

Le chef des équipages, Ahmosé, fils d'Abana, juste de voix, parle:

"Je vais raconter à vous tous, je vais vous faire savoir les honneurs qui me sont échus. Je suis quelqu'un qui a été récompensé par l'or sept fois devant le pays tout entier, également par des esclaves hommes et femmes, et qui a été pourvu de nombreuses et grandes terres. Le nom d'un brave est dans ses actes; ainsi il ne sera jamais oublié dans ce pays.»

Il continue en disant:

"Je fus élevé dans la cité de Nekheb $(e l-K a b)$. Mon père était soldat du roi de Haute et de Basse-Égypte Séqénenrê, juste de voix. Son nom était Baba, fils de Raïnet. Je le remplaçai comme soldat sur le vaisseau "Le Taureau sauvage», sous le règne du Seigneur des Deux Terres Ahmosis, juste de voix. J'étais alors un adolescent qui n'avait pas pris femme. Je dormais dans un hamac.

Après avoir fondé un foyer, je fus muté dans la flotte du nord (ou sur le vaisseau "Celui du nord») grâce à ma bravoure, et je suivis le souverain (vie, santé, force) à pied quand il allait et venait sur son char pendant le siège de la ville d'Avaris (capitale des Hyksôs). Je fis preuve de bravoure comme fantassin en présence de Sa Majesté. Je fus affecté alors sur le vaisseau Kha-em-Men-nefer ("Celui qui apparaît à Memphis»).

Il y eut un combat naval sur le canal d'Avaris nommé Padjedkou. Je fis du butin et rapportai une main (la main coupée d'un ennemi abattu). Comme ce fut relaté au héraut royal, on m'accorda l'or de la bravoure. Puis on reprit les combats en ce lieu et, à nouveau, je fis du butin et rapportai une main. On m'accorda encore l'or de la bravoure.

Ensuite, on combattit en Égypte, au sud de cette ville (Avaris). Je ramenai un prisonnier: j'étais descendu dans l'eau, car sa capture s'est faite sur le chemin de l'embarcadère, et je traversai l'eau en le portant. Ce fut relaté au héraut royal et je fus récompensé par l'or une nouvelle fois.

Puis ce fut la prise d'Avaris. J'y capturai un homme et trois femmes, soit au total quatre personnes. Sa Majesté me les donna comme esclaves.

Alors on mit le siège devant (la ville de) Sharouhen pendant trois ans. Lorsque Sa Majesté la prit enfin, j'en rapportai du butin : deux femmes et une main. On m'accorda l'or de la bravoure et on me donna mes prisonnières comme esclaves.

Après que Sa Majesté eut massacré les Nomades d'Asie, Elle remonta le fleuve vers la ville de Khenet-hen-nefer pour détruire les Archers de Nubie. 


\section{0}

Sa Majesté en fit un grand carnage. Pour ma part, j'en rapportai du butin, à savoir deux hommes vivants et trois mains. Je fus une nouvelle fois récompensé par l'or et on me donna deux femmes esclaves.

Ensuite Sa Majesté navigua vers le nord, le cœur gonflé de joie par ces combats victorieux au terme desquels il avait conquis le sud et le nord.

Puis l'ennemi Aata vint au sud. Son destin engendra sa perte. Les dieux de Haute-Égypte s'emparèrent de lui. Sa Majesté le trouva à Tinet-taâ (un lieu sur le Nil). Sa Majesté le fit prisonnier. Tous ses gens furent capturés. Je m'emparai de deux rebelles sur le bateau d'Aata. On me donna cinq esclaves et des lopins de terre, en tout cinq aroures ( $4 \mathrm{ha}$ ) dans ma ville. On agit semblablement pour l'ensemble des équipages.

Ensuite vint cet ennemi nommé Tétian. Il avait rassemblé autour de lui des gens pleins de félonie. Sa Majesté le tua. Son entourage cessa d'exister. On me donna trois esclaves et cinq aroures ( 4 ha) dans ma ville.

Ensuite, je transportai en bateau le roi de Haute et Basse-Égypte Djeserkarê (Amenhotep Irr), juste de voix, quand il remonta le Nil vers Koush pour étendre les frontières de l'Égypte.

Sa Majesté s'empara de cet archer nubien au milieu de son armée. On le mit dans les chaînes. Aucun n’y échappa, les fugitifs étant anéantis, comme s'ils n'avaient jamais existé.

Alors, je pris place parmi les troupes d'élite de notre armée parce que j'avais fait preuve d'une bravoure remarquable qui n'avait pas échappé à Sa Majesté. J'avais rapporté deux mains qui furent présentées à Sa Majesté.

des origines

à la chute du sultanat Fung Alors que l'on cherchait ses gens et ses troupeaux, je capturai un prisonnier qui fut présenté à Sa Majesté.

Je transportai Sa Majesté en Égypte en deux jours, depuis le Puits-d'en-haut. Je fus récompensé par l'or, et on m'amena deux femmes esclaves tirées du butin, sans compter celles que j'avais fait présenter à $\mathrm{Sa}$ Majesté. On me nomma "combattant du souverain".

Puis je transportai en bateau le roi de Haute et Basse-Égypte Âa-kheper-ka-Rê (Thoutmosis Irr), juste de voix, quand il remonta le Nil vers la ville de Khenet-hen-nefer, afin de détruire la rébellion à travers les pays étrangers et de repousser les invasions depuis le désert. Je fis preuve de courage en Sa présence quand il fallut forcer le passage en bateau dans les eaux dangereuses de la cataracte, si bien que l'on me nomma «chef des équipages".

Alors Sa Majesté (vie, santé, force)... (lacune d'une ligne). Sur ce, Sa Majesté devint enragée comme une panthère; Elle lança sa première flèche qui se fixa dans la poitrine de cet ennemi. Alors ces [rebelles fuirent], pris de panique devant son uræus (cobra royal fixé sur la couronne). 
On fit ensuite un carnage parmi eux et leurs gens furent faits prisonniers. Sa Majesté vogua ensuite vers le nord, ayant saisi dans Son poing tous les pays étrangers, et, sur la proue du vaisseau le «Faucon», le vaisseau de Sa Majesté, ce misérable Nubien était [attaché] la tête en bas, jusqu’à ce que l'on aborde à Ipet-Sout [Karnak].

Après ces événements, il y eut une expédition vers le Retjenou (Syrie) pour apaiser sa colère contre les pays étrangers. Lorsqu'Elle parvint à Naharina (Mittani), Sa Majesté (vie, santé, force) trouva cet ennemi en train de rassembler ses troupes. Sa Majesté en fit un grand carnage. Innombrables furent les prisonniers que Sa Majesté ramena de ses victoires. J'étais dans les troupes d'élite et Sa Majesté vit ma bravoure, car je ramenai un char, son cheval et son conducteur prisonnier, ce qui fut rapporté à Sa Majesté. Une nouvelle fois, je fus récompensé par l'or.

Je suis devenu vieux. J'ai atteint le grand âge et ai continué à recevoir les mêmes faveurs et l'amitié de [mon souverain]. Je repose désormais dans la tombe que j'ai fait construire moi-même.

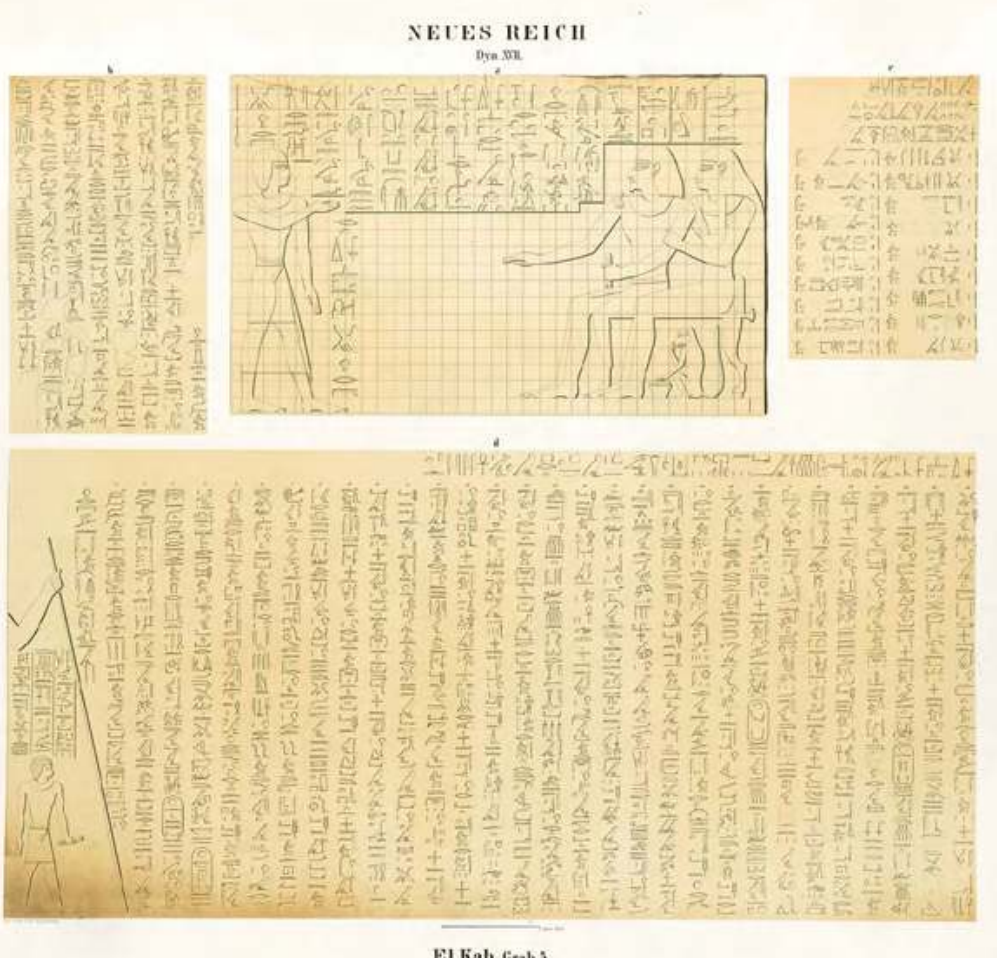

Autobiographie d'Ahmose, fils d'Abana.

Tombe d'el-Kab, vers 1645 av. J.-C., d'après Carl Richard Lepsius,

Denkmäler aus Aegypten und Aethiopien, vol. III, pl. 12. 


\section{La défaite du royaume de Kerma}

Sous le règne suivant, celui de Thoutmosis I ${ }^{\text {er }}$ l'expédition contre Koush, lancée dès l'an 2 (à placer sans doute peu avant 1500 av. J.-C.), prit une toute autre ampleur et porta un coup sévère au royaume de Kerma. Ahmosé, maintenant cinquantenaire, ne s'illustra plus sur les champs de bataille mais mit à profit sa longue expérience de marinier pour conduire en sûreté la flotte royale à travers les rapides de la cataracte. Sans doute s'agissait-il de la troisième, que les Égyptiens abordaient en effet pour la première fois. Cet exploit lui valut d'être promu au rang de "chef des équipages» (parfois traduit aussi par «amiral»), le plus haut grade qu'il atteignit dans sa longue carrière. L'année suivante, parvenu avec les troupes égyptiennes jusqu'au Mittani, royaume situé au nord de l'Euphrate, il terminera ce parcours brillant à la tête d'un détachement, amenant un attelage ennemi et son aurige prisonnier devant le souverain.

Si les campagnes de Nubie des pharaons précédents sont mal connues en dehors de ce témoignage, celle de Thoutmosis ${ }^{\mathrm{er}}$ est détaillée par des inscriptions officielles et confirmée par l'archéologie. Dans son autobiographie, Ahmosé, fils d'Abana, décrit la mise à mort du chef des armées nubiennes, dont le cadavre est ramené jusqu’à Thèbes, fixé dans une position infâmante à la coque du vaisseau royal. S'agissait-il cette fois du roi de Kerma? On serait tenté de le croire, mais le texte qui le désigne comme "cet ennemi » ou "ce misérable Nubien" est très imprécis.

Deux sites du Soudan ont gardé la trace écrite de la conquête

des origines

à la chute

du sultanat

Fung égyptienne. À quelques kilomètres au nord de Kerma, au centre de la troisième cataracte, les rochers granitiques de Tombos sur la berge du Nil sont ainsi gravés de panneaux hiéroglyphiques de grandes dimensions proclamant la victoire de Thoutmosis ${ }^{\text {er }}$ sur les Nubiens (Nhsy.w). Un peu en retrait du fleuve, sous le couvert des arbustes, un ensemble de blocs portent des inscriptions datées de différents souverains de la XVIII $^{\mathrm{e}}$ dynastie, dont une très grande au nom de Thoutmosis $\mathrm{I}^{\mathrm{er}}$. Cette "stèle " de Tombos narre la victoire des armées de Pharaon avec un luxe de détails sanguinolents. Elle indique que le roi de Kerma a été "renversé» mais non pas qu'il a été tué, ce qui laisse supposer que le cadavre ramené en Égypte est sans doute celui du général ennemi. Dans une stèle ultérieure de Thoutmosis II, le scribe précisera d'ailleurs que le roi de Kerma avait fui et non qu'il avait perdu la vie.

L'autre site se trouve très loin en amont, à proximité de la cinquième cataracte, peu avant la grande boucle en « $S$ » du Nil. Près du village de Kourgous s'élève dans la plaine une haute roche blanche, appelée Hajrel-Merwa, où des inscriptions ont été gravées par les Égyptiens aux noms 
de Thoutmosis I ${ }^{\text {er }}$ et Thoutmosis III. Autour de la représentation d'un lion en marche, le premier texte proclame que la frontière de l'Empire a été fixée en ce lieu et énumère les malédictions qui pèseraient contre les ennemis qui la transgresseraient. Il est toutefois assez vraisemblable que la mainmise sur cette région se soit faite par une seconde expédition empruntant la route du désert depuis Korosko. Cette tactique consistant à prendre en tenaille le territoire nubien des deux côtés de la grande boucle est dictée par la géographie même de la vallée du Nil. On suppose que c'est ainsi que procéda le pharaon Psammétique II en 591 av. J.-C. lorsqu'il ravagea le royaume de Napata. Le général anglais Kitchener, lors de sa campagne de 1897-1898 contre l'État mahdiste au Soudan, a également employé cette stratégie. Du coup, on ne peut certifier que l'ensemble du territoire kermaïte passa sous le contrôle des Égyptiens.

L'archéologie récente confirme en tout cas la prise de la capitale sous le règne de Thoutmosis I ${ }^{\text {er. }}$ En 1994, les travaux de l'université de Genève à Kerma se sont en effet portés sur un endroit situé à un kilomètre au nord de la cité royale, marqué par un kôm couvert de tessons de céramique dont la couleur explique le nom: Doukki Gel, en nubien moderne «la butte rouge». La fouille sous la direction de Salah el-Din Mohammed Ahmed et de Charles Bonnet révéla assez rapidement un impressionnant ensemble cultuel égyptien, complété ou rebâti à de nombreuses reprises durant la XVIII ${ }^{e}$ dynastie, puis aux époques napatéenne et méroïtique. Les premiers temples, totalement refaits sous la reine Hatchepsout, avaient été bâtis sous le règne de son père Thoutmosis $\mathrm{I}^{\mathrm{I}}$. Au fur et à mesure que les travaux des archéologues avançaient vers le sud et l'est de l'ensemble central, de nouveaux bâtiments furent dégagés. Tout d'abord, des temples locaux, de forme circulaire et entourés de bastions. Bien que fondés avant la conquête, détruits puis rebâtis, ils ont continué à fonctionner en même temps que les sanctuaires pharaoniques, ce qui laisse supposer que les deux cultes, égyptien et koushite, ont finalement pu coexister pacifiquement. Ensuite, deux palais cérémoniels sont apparus au sud-ouest et au nord-est des constructions pharaoniques. Édifiés également sous Thoutmosis I ${ }^{\mathrm{er}}$, ils forment avec les trois temples contemporains un complexe entouré de puissants bastions qui correspond à ce que les Égyptiens appelaient un «ménénou », c'est-à-dire un centre administratif et religieux fortifié sur les marches de l'Empire.

Plus récemment encore, depuis 2012, de vastes palais cérémoniels en brique crue ont été mis au jour sur le site de Doukki Gel. Il s'agit d'édifices circulaires, renforcés d'épais bastions et comportant un nombre extraordinaire de colonnes très rapprochées qui limitaient la circulation à l'intérieur. Cette architecture étonnante n'est pas attestée dans la cité 
royale de Kerma. Les seuls parallèles connus sont lointains et tardifs, comme le mausolée des rois du Buganda à Kasubi, près de Kampala, qui remonte au XIX ${ }^{\mathrm{e}}$ siècle.

Charles Bonnet et Dominique Valbelle ont émis l'hypothèse que ces palais aient appartenu aux chefs d'une coalition rassemblée par les derniers souverains de Kerma. L'inscription de la tombe de Sobeknakht à el-Kab atteste l'attaque, sous la XVII ${ }^{e}$ dynastie, d'armées où plusieurs ethnies, dont les Medjay et les gens de Pount, étaient rassemblées autour des guerriers de Koush. De plus, dans la stèle de Tombos citée ci-dessus, Thoutmosis $I^{\text {er }}$ mentionne des auxiliaires venus aider le souverain de Kerma, sans préciser leur origine. Or, les premiers palais retrouvés à Doukki Gel sont clairement datés, grâce à la céramique, de la période finale du royaume. Cette hypothèse reste néanmoins fragile et il faut espérer que de nouveaux éléments viendront la corroborer.

La destruction de la capitale et l'édification d'un complexe fortifié ne donneront toutefois pas le coup de grâce au royaume de Kerma. Dès l'an 3, Thoutmosis ${ }^{\text {er }}$ quitte en effet la Nubie et laisse le vice-roi Touro, le premier «fils royal» (l'adjonction «de Koush» se fera un siècle plus tard), auparavant commandant de la forteresse de Bouhen, administrer la nouvelle colonie. S'acquitta-t-il de cette tâche à la satisfaction de son souverain? La suite des événements laisse supposer que non. Il est d'ailleurs vite remplacé par un nouveau vice-roi, Seni.

Dix ans après l'expédition contre Kerma menée par Thoutmosis I ${ }^{\mathrm{er}}$, son fils Thoutmosis II monte sur le trône, sans doute à un très jeune âge. des origines à la chute du sultanat Fung Dès sa première année de règne, il est informé que Koush s'est ressaisie, bien que divisée en trois principautés indépendantes dirigées par les enfants du souverain précédent. La stèle d'Assouan qui relate ce sursaut des Koushites précise que les «ménénou» construits sur l’ordre de Thoutmosis ${ }^{\mathrm{er}}$ sont victimes d'attaques où des hommes et des troupeaux sont razziés. La situation était bien plus grave puisque les bâtiments égyptiens de Doukki Gel avaient été détruits, alors que la cité de Kerma, incendiée durant la campagne précédente, était partiellement restaurée.

La réaction du nouveau pharaon ne se fit pas attendre. Il envoya ses troupes et mit fin à la révolte, écrasant les Koushites, vraisemblablement fragilisés par la division du pays en trois royaumes. On ne ramena vivant que l'un des jeunes princes et son escorte, sans doute pour le rééduquer à l'égyptienne dans ces écoles appelées kap, avant de le renvoyer comme administrateur dans son pays, une pratique qui se répandit sous la XVIII e dynastie. 


\section{L'établissement de l'administration égyptienne}

La campagne de Thoutmosis II fut suivie d'une autre, sans doute vers $1470 \mathrm{av}$. J.-C., sous le règne de son épouse Hatchepsout. Il semble que ces opérations mirent un terme à l'instabilité de la conquête. Plusieurs opérations militaires sont signalées sous les règnes suivants mais elles ne paraissent pas avoir revêtu l'ampleur des précédentes. La cité de Kerma fut définitivement abandonnée et le ménénou de Doukki Gel, reconstruit sur une échelle plus ambitieuse. Les forteresses de Basse-Nubie bâties sous le Moyen Empire, que les premiers pharaons de la XVIII ${ }^{e}$ dynastie avaient en partie restaurées, furent dotées de temples en grès à Qoubban, Koumma et surtout Bouhen. Sur ce dernier site, la reine Hatchepsout fit bâtir pour le dieu Horus un superbe édifice entouré de colonnes, précédé d'une cour hypostyle et orné de peintures splendides que l'on peut encore admirer dans les jardins du musée de Khartoum où ces sanctuaires ont été remontés durant la campagne de sauvetage des monuments de Nubie consécutive à l'érection du haut barrage d'Assouan. À Koumma, aux abords de la deuxième cataracte, un nouveau temple fut consacré aux dieux égyptiens adorés près d'Assouan, Khnoum et Dédoun, mais on leur adjoignit le culte de Sésostris III divinisé, afin de placer la nouvelle conquête sous le patronage du pharaon qui, au Moyen Empire, avait assuré la mainmise de l'Égypte sur la Basse-Nubie et achevé la construction des forteresses qui protégeaient la nouvelle frontière.

Thoutmosis III mena plusieurs expéditions en Nubie, la plupart en tant que chef d'armée de sa tante et corégente Hatchepsout. La quatrième est fameuse pour la chasse au rhinocéros qu'il fit représenter dans le temple d'Ermant en Égypte. Sur le rocher de Kourgous, entre la quatrième et la cinquième cataracte, à côté de l'inscription de son aïeul Thoutmosis Ir, il en fit graver une presque identique où il figure également comme un lion en marche. Soucieux d'établir sa domination sur la totalité de l'ancien royaume de Kerma, il fonda des centres religieux et administratifs dans des lieux jusqu'alors peu touchés par la domination égyptienne et qui avaient peut-être servi de refuges face aux expéditions pharaoniques. C'est notamment le cas de Napata, au milieu de la grande boucle du Nil, où il établit un ménénou appelé justement "celui qui extermine les habitants du désert" (une désignation habituelle des étrangers hostiles), comme le rappelle une stèle de l'an 47 (soit la $25^{\mathrm{e}}$ année de son règne personnel) retrouvée en ce lieu. C'est sous son règne que commence, en effet, au pied du Gébel Barkal déjà désigné dans la stèle comme la «montagne pure», l'édification de sanctuaires qui se continuera jusqu'à l'époque méroïtique. Aujourd'hui encore, bien que cerné par les faubourgs de la ville moderne de Karima et enlaidi par la construction d'une route goudronnée qui le contourne, le site du Gébel Barkal garde 
le Soudan

\section{6}

des origines

à la chute

du sultanat

Fung

une aura qui impressionne toujours le visiteur. Ce massif de grès isolé, culminant à $90 \mathrm{~m}$ au-dessus de la plaine sur la rive droite du Nil, est un relief tabulaire de forme très régulière, avec des falaises abruptes sur trois de ses côtés. Au sud, il est flanqué d'une aiguille inaccessible de $70 \mathrm{~m}$ de hauteur dont le contour, par un caprice de la nature, évoque un personnage debout, coiffé de la couronne blanche de Haute-Égypte (voir p.125 sq.). Les Égyptiens y virent la silhouette d'un cobra royal dressé, comme celui qu'arborent les couronnes pharaoniques, ainsi que l'atteste la représentation de cette «montagne pure» dans le temple d'Abou Simbel érigé par Ramsès II deux siècles plus tard. Le dieu Amon y est figuré assis sous un dais qui évoque le relief du gébel, précédé d'un large cobra coiffé de la couronne blanche. Plus tard encore, à la fin de la XXVe dynastie, le pharaon koushite Taharqo fera bâtir dans le gébel un hémispéos (temple en partie creusé dans la falaise) où il est représenté face à Amon de Napata, semblablement assis dans la montagne flanquée du cobra, coiffé cette fois d'un disque solaire. Le gébel est ainsi supposé abriter une des résidences du dieu. Cette origine nubienne d'Amon apparaît çà et là dans les textes égyptiens. Elle y est parfois liée, comme dans un ostracon de Deir el-Medineh, à l'origine de la crue venue également du sud. Elle constitue aussi une revendication de légitimité sur le territoire soudanais, le pharaon étant fils d'Amon et donc l'héritier de son pays d'origine. Les pharaons koushites de la $X X X V^{e}$ dynastie, originaires du Soudan, sauront très habilement retourner l'argument pour asseoir leur légitimité sur le trône d'Égypte.

Dans ses deux représentations citées ci-dessus, Amon de Napata est figuré avec une tête de bélier. C'est sous la XVIII dynastie qu'apparaît cette forme dite "criocéphale» du dieu. Il s'agit manifestement d'une spécificité nubienne dès l'origine. Certes, les Égyptiens connaissent déjà un dieu criocéphale, Khnoum, maître d'Éléphantine. Mais il est représenté avec des cornes horizontales torsadées, qui correspondent à la ramure de la race dite ovis aries longipes. La forme d'Amon criocéphale présente une race différente, dite ovis aries platyura, aux cornes recourbées en spirale. Amon est figuré tout au long de l'histoire égyptienne comme un dieu d'apparence totalement humaine, dont l'unique trait caractéristique est la coiffure composée d'un mortier et de deux hautes plumes. Le seul animal qui lui est associé avant le Nouvel Empire est l'oie. En revanche, le dieu principal de la religion kermaïte était très certainement un bélier, comme nous l'avons vu au chapitre précédent. La fusion des deux divinités principales du panthéon égyptien et du panthéon local et la reconnaissance par le pouvoir pharaonique de cette nouvelle forme du dieu

Temple de Semna, Dédoun et le roi Thoutmosis III. dynastique font sans doute partie d'une politique de conciliation des élites locales qui contrebalançait la domination par la force. Cette représentation d'Amon restera d'ailleurs rare sur le sol égyptien proprement dit, à l'exception de l'allée de béliers qu'Amenhotep III fit ériger à Karnak. Nous avons 


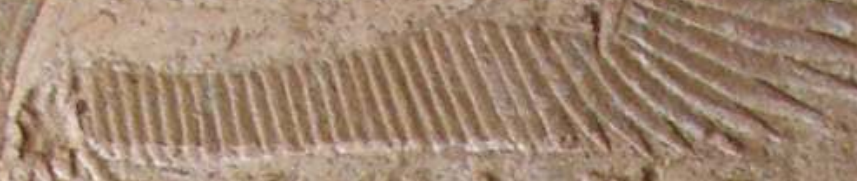 \\ min}

(2) 514

- 10

2. 1 inimas

In 2,3

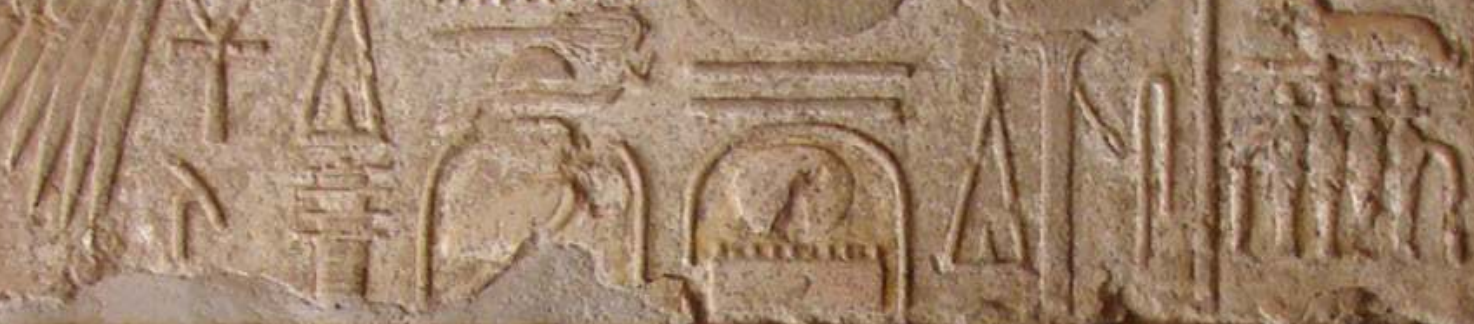
Est
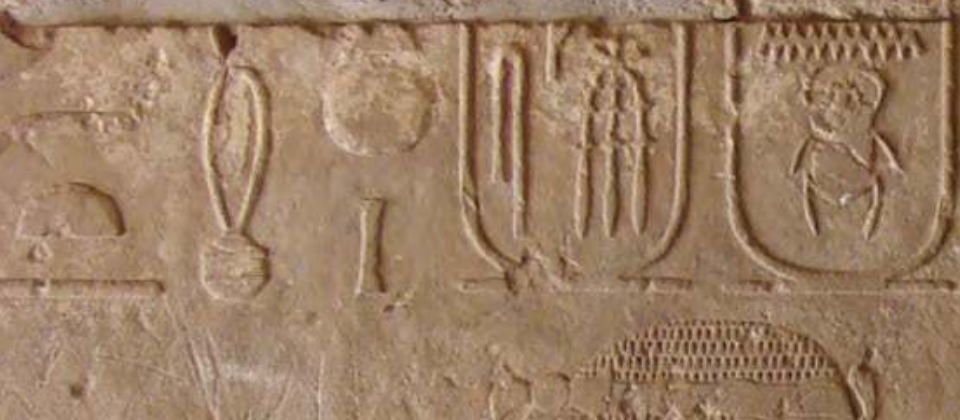

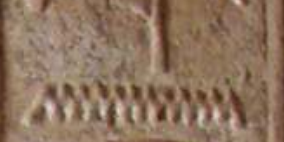

27.

Uाग

(5)

(iis)
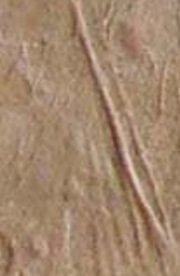

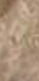

6

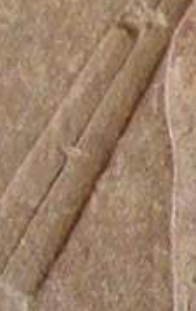
$\cos x$

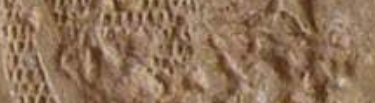

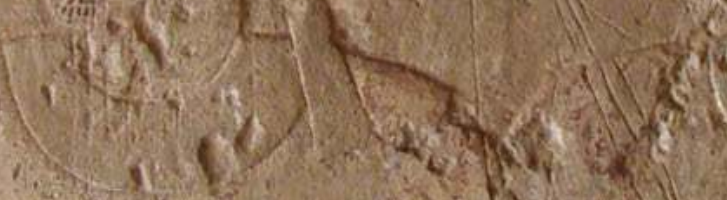

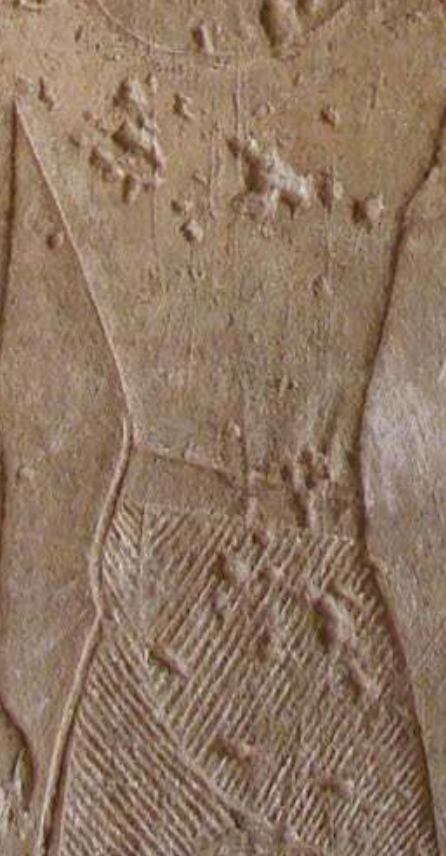

60
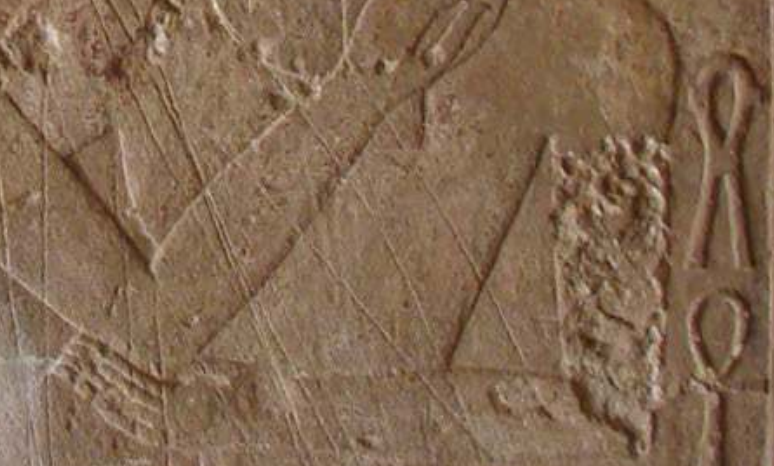

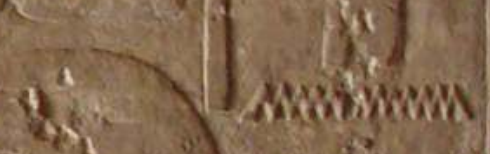

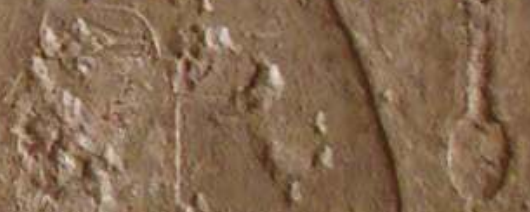



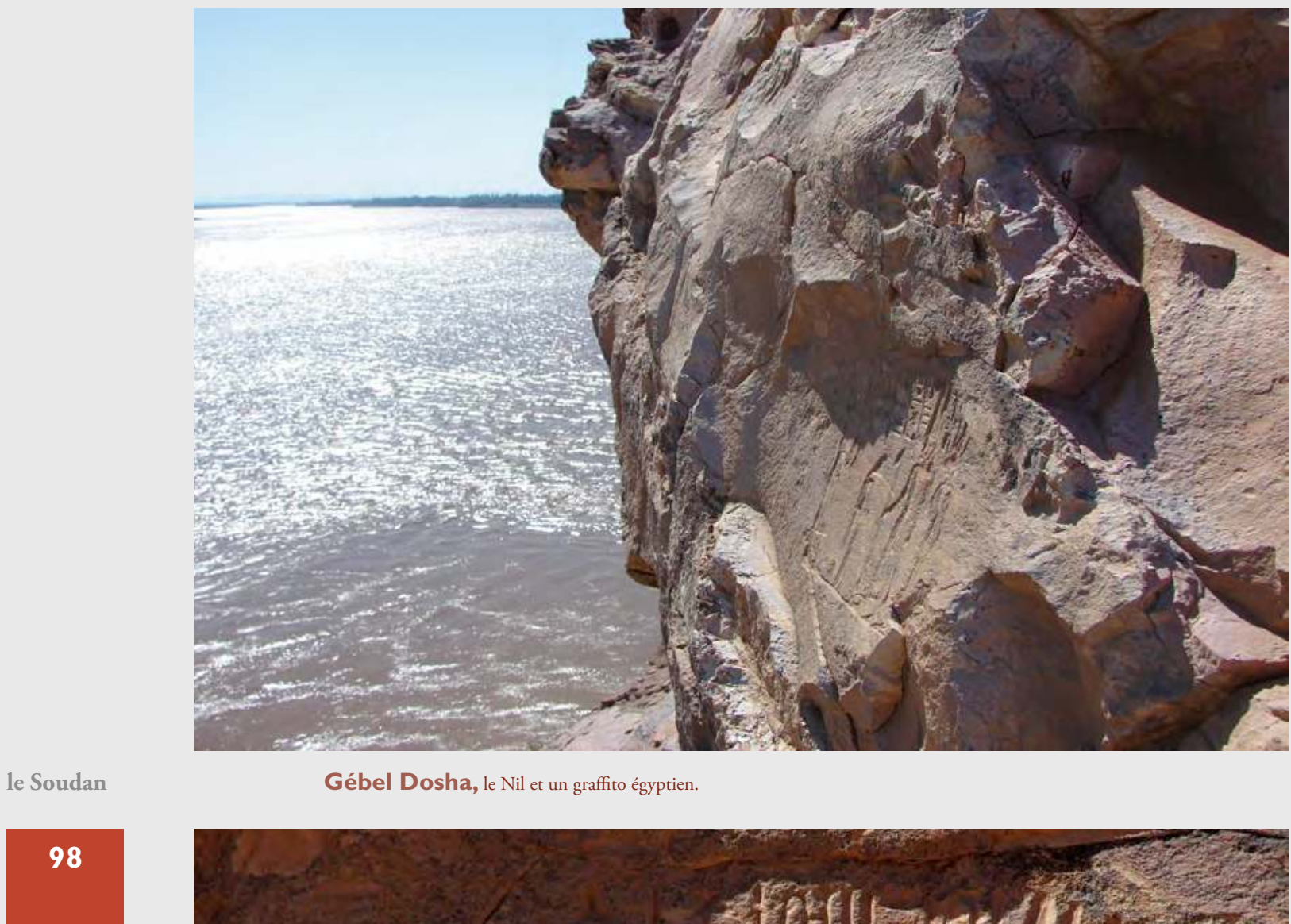

des origines à la chute du sultanat Fung

\section{Gébel Dosha, le Nil et un graffito égyptien.}

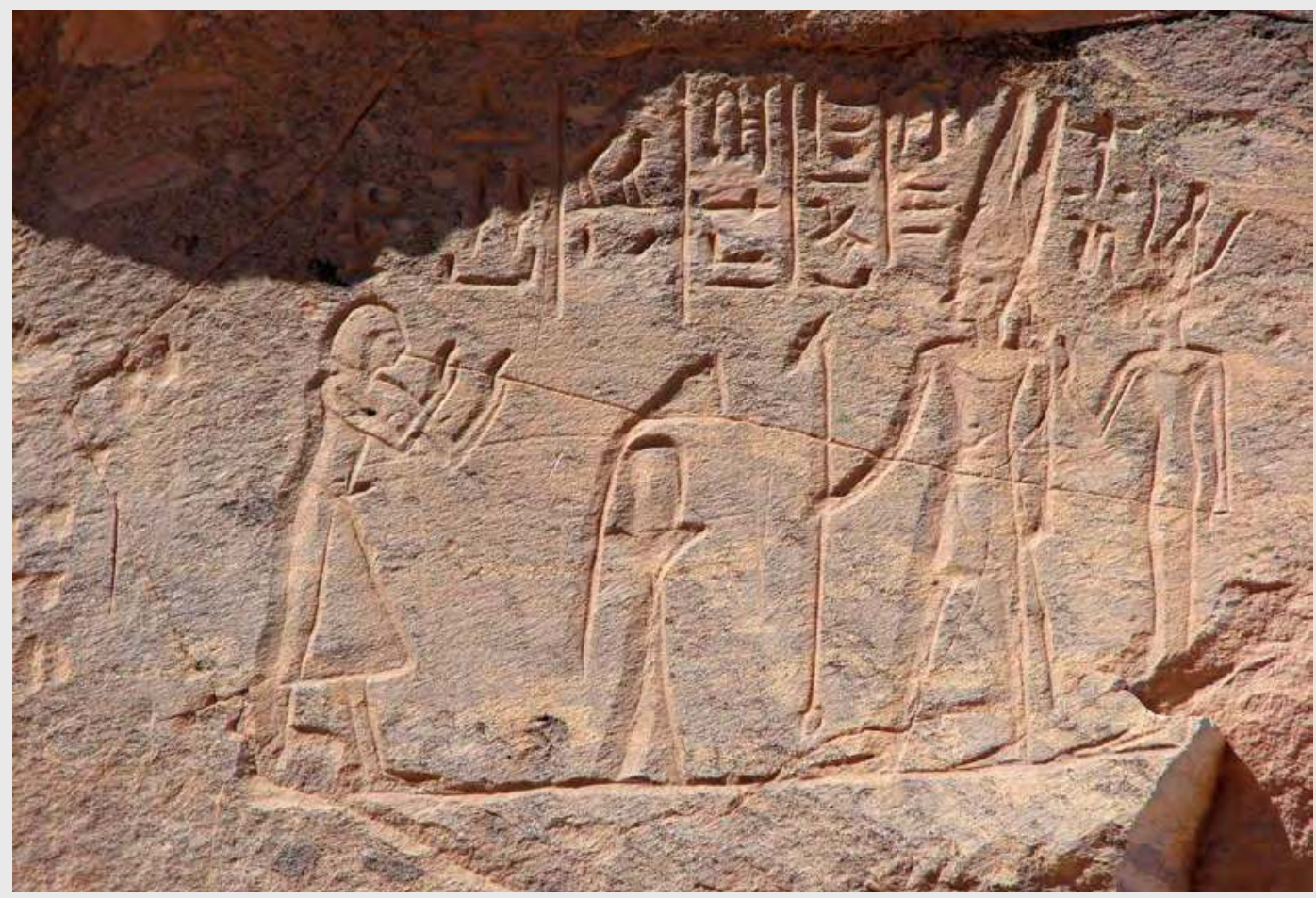

Gébel Dosha, inscription du scribe Keny. 
vu que, semblablement, les temples locaux de Doukki Gel avaient été rebâtis après les destructions de la conquête, formant un véritable quartier religieux koushite à l'ouest du complexe cultuel égyptien.

La ville de Kerma/Doukki Gel, sous son nom égyptien de Pnoubs (transcription grecque tardive de $P \jmath-n b s$ «le jujubier»), loin d'être rayée de la carte, connaîtra ainsi un nouvel essor sous la domination égyptienne. C'est également sous Thoutmosis III qu'est entreprise la construction d'un temple d'Amon en pierre sur l'île de Saï. En Moyenne-Nubie, dans la région où Amenhotep III fera construire Soleb et Sedeinga, le spéos (temple rupestre) du Gébel Dosha a été également fondé par Thoutmosis III, dont le cartouche apparaît sur les murs du sanctuaire. Les travaux archéologiques menés à partir de l'hiver 2015 sur ce site le confirmeront peutêtre. Enfin, en Basse-Nubie, Thoutmosis III fit bâtir à Semna un nouveau temple dédié à Sésostris III divinisé et au dieu Dédoun «qui préside à la Terre de l'Arc». À Koumma et à Bouhen, il fit effacer les cartouches de la reine Hatchepsout et les fit remplacer par le nom de son père Thoutmosis II ou le sien. Cette damnatio memoriae est attestée sur l'ensemble de l'Empire. Bien que tardive durant le règne personnel de Thoutmosis III, elle est généralement interprétée comme un déni de légitimité à l'égard d'une régente qui se proclama roi (et fut d'ailleurs représentée comme un pharaon mâle), spoliant les droits de l'héritier légitime.

Sur le plan administratif, de nouveaux «fils royaux», vice-rois de Nubie, furent nommés, Nehi dès le règne de Hatchepsout, puis Paenrê sous Thoutmosis III. On ne saurait voir en eux des administrateurs coloniaux: ils résident en effet à Thèbes, où ont été retrouvées la plupart de leurs sépultures, et sont parfois en charge également des nomes (provinces) les plus méridionaux d'Égypte, au nord d'Assouan. Leur rôle principal est d'assurer l'acheminement auprès de Pharaon du tribut dû par les deux provinces nubiennes de Wawat (Basse-Nubie) et Koush (tout le sud de la colonie). Dans le tribut de Wawat figure l'apport le plus précieux, l'or extrait des mines du Wadi Allaqi et du Wadi Gabgaba, situées dans le désert Arabique à l'est de Qoubban. Grâce à l'affermissement de la domination égyptienne, le tribut de Nubie rentra régulièrement et nous en possédons des attestations pour presque toutes les années entre l'an 31 et 42 de Thoutmosis III. Les vice-rois accomplissent des tournées régulières en Nubie, mais ils y seront un peu plus tard représentés de manière permanente par deux gouverneurs délégués, l'un à Aniba (au nord d'Abou Simbel) pour la province de Wawat et l'autre à Soleb puis à Amara, au nord de l'île de Saï. La gestion des nouveaux territoires n'est pas sans rappeler l'indirect rule, la politique coloniale de l'Empire britannique. Si les plus hauts échelons de la direction des provinces et des temples sont tenus par des fonctionnaires égyptiens, ils font largement appel aux élites locales 
pour administrer le quotidien. On sait par exemple qu'en Basse-Nubie il continue d'exister des principautés indigènes comme Miam, Baket ou Teh-Khet, avec à leur tête des dynasties de potentats locaux étroitement contrôlés par le pouvoir colonial et souvent fortement égyptianisés. Certains des gouverneurs de Wawat et de Koush sont eux aussi d'origine nubienne.

Au sud de Kerma/Pnoubs, aucune attestation n'a été trouvée jusqu'ici de l'autorité des vice-rois ou de leurs délégués. On ignore comment étaient gérées ces régions, que les textes égyptiens appellent Karoy et Irem, sans que nous puissions exactement connaître leur extension géographique. La seule entité coloniale connue est le "ménénou» fondé au Gébel Barkal qui, comme tous ces types d'établissement, disposait de sa propre administration. Karoy était une région riche en or, peut-être située autour de la cinquième cataracte, qui contribuait au tribut nubien. Irem compte parmi les ennemis de l'Égypte contre lesquels des opérations militaires étaient régulièrement entreprises, y compris par Thoutmosis III qui en ramena quatre princes prisonniers en Égypte. Beaucoup plus au sud encore, sans doute entre l'actuel Kassala à l'est du Soudan et la côte érythréenne, se trouvait le pays de Pount dont le territoire sans doute s'étendait aussi de l'autre côté de la mer Rouge. Situé hors de la zone d'influence de l'Égypte, il était atteint durant le Moyen Empire par des expéditions maritimes au départ du port égyptien de Mersa Gawasis, notamment pour rapporter l'oliban, l'encens véritable, indispensable au culte des dieux. Sous le règne d'Hatchepsout, une nouvelle expédition fut organisée, comme l'attestent les reliefs bien connus du temple de la reine à Deir el-Bahari. Bien que le point soit discuté, le voyage se fit proba-

des origines

à la chute

du sultanat

Fung blement à nouveau par la mer Rouge. Toutefois, des mentions du "tribut" de Pount sont attestées durant les règnes suivants, sans que l'on ait trace de nouvelles expéditions maritimes. Le terme de «tribut» (égyptien jnw) est évidemment une exagération de la propagande royale, et les biens ainsi acquis l'ont été très probablement par des échanges. Il n'est pas impossible qu'ils se soient faits cette fois par voie terrestre, auquel cas il faut supposer que des réseaux d'échange incluant les contrées entre Koush et l'est du Soudan, comme il en existait sous l'Ancien Empire (voir le récit de Herkhouf au chapitre précédent, p. 73 sq.), aient été rétablis.

\section{La Nubie à la fin de la XVIII dynastie}

Durant la seconde moitié de la XVIII ${ }^{e}$ dynastie, l'emprise de l'Égypte sur la Nubie ne fit que se consolider. Les opérations militaires devinrent plus rares. Dans une stèle retrouvée à Amada et datée de l'an 7 (vers 1420 av. J.-C.) d'Amenhotep II, fils et successeur de Thoutmosis III, on trouve cet étonnant passage qui relate comment ce roi, réputé pour ses performances 
physiques, tua de sa masse d'armes sept chefs ennemis, durant la campagne menée en Syrie. Leurs cadavres furent fixés à la proue des navires jusqu'au retour à Thèbes. Les corps furent exhibés sur les murs de la capitale égyptienne, mais l'un d'entre eux fut amené jusqu'en Nubie. Il fut suspendu aux murailles du ménénou du Gébel Barkal, désigné, pour la première fois dans l'histoire, du nom de "Napata». Cette macabre démonstration de puissance, destinée à décourager les révoltes, rappelle évidemment le traitement réservé au corps du général ennemi lors de la grande campagne de Nubie de son bisaïeul Thoutmosis Ir. Durant son règne, Amenhotep II nomma un nouveau vice-roi en la personne d'Ousersatet. Plusieurs de ses inscriptions ont été retrouvées, dont une stèle de Semna, aujourd'hui au musée de Boston. Son contenu est particulièrement intéressant mais, hélas, comporte des passages assez obscurs. Ousersatet y cite en effet une lettre officielle envoyée par le pharaon en l'an 23 à l'occasion de l'anniversaire de son accession au trône et rédigée "au moment où il se mettait à boire et à célébrer la fête». L'étrangeté de certaines parties du message, les invectives réelles ou supposées à l'égard des peuples ennemis ou conquis ont conduit quelques égyptologues à accuser Amenhotep II de «racisme», voire d'avancer que la lettre a été rédigée sous l'effet de l'ivresse.

Une étude publiée en 2014 par John C. Darnell tente de mettre de l'ordre dans l'interprétation du texte et de dédouaner le pharaon des accusations dont il a été l'objet. Le souverain rappelle en introduction la vaillance du futur vice-roi durant les combats de Syrie, détaille les servantes originaires de cette région qui lui ont été données en butin, lui conseille de ne pas montrer d'indulgence envers les Nubiens et de se méfier d'eux et de leurs magiciens. Il termine par l'évocation peu claire, illustrée de plus par une métaphore complexe, des questions de recrutement local dans le personnel administratif du vice-roi. Si difficile qu'elle soit à interpréter, la stèle d'Ousersatet nous livre de précieuses informations sur l'administration égyptienne des territoires nubiens. Le vice-roi est choisi parmi les serviteurs les plus sûrs du souverain, qui le connaît personnellement et se tient parfaitement informé de tous ses faits et gestes. Ce lien très étroit explique le titre étonnant de «fils royal» pour un haut fonctionnaire qui n'est jamais de sang dynastique: il se doit d'avoir envers le monarque la loyauté qu'un fils aurait envers son père. S'il lui faut tenir d'une main de fer les nouveaux sujets de Pharaon, il associe les élites nubiennes à l'administration de la colonie. En retour de la confiance royale, il est tenu de tout faire pour que le tribut annuel de Wawat et de Koush soit apporté devant le souverain, ainsi que l'illustre la lunette de la stèle d'Ousersatet où l'on voit le vice-roi offrant à Amenhotep II, qui trône sous un dais, les produits de la colonie et, avant tout, l'or sous forme de colliers. 
Alors qu'Amenhotep II et son successeur Thoutmosis IV ont essentiellement construit en Basse-Nubie et sur une échelle relativement réduite, le long règne d'Amenhotep III (vers 1390 à 1352 av. J.-C.) voit l'édification du plus grand temple égyptien du Soudan, celui de Soleb. Cet édifice grandiose, mesurant à l'origine $172 \mathrm{~m}$ de longueur (depuis le pylône extérieur), fait partie des trois réalisations architecturales majeures de ce pharaon bâtisseur, avec le temple de Louxor et celui de Kôm el-Hettan, connu par les colosses de Memnon. Il fut achevé pour la commémoration du premier jubilé ( «ête Sed») d'Amenhotep III, marquant ses trente ans de règne, et était consacré à Amon et à Nebmaâtrê, la forme divinisée du pharaon, portant son nom de couronnement. Il comportait une allée monumentale ornée de statues de bélier, figures de l'Amon nubien, et de deux lions de granit rouge, aujourd'hui au British Museum. Un autre temple de moindre dimension fut érigé à $14 \mathrm{~km}$ au nord, sur le site de Sedeinga. Il était dédié à la reine Tiyi, grande épouse royale d'Amenhotep III, mais également à Nebmaâtrê dont le cartouche apparait en hiéroglyphes géants sur les architraves, comme à Soleb. La question se pose de savoir pourquoi ce pharaon choisit cette région isolée entre deuxième et troisième cataracte pour y édifier un ensemble architectural qui dépasse de loin toutes les autres constructions - essentiellement des aménagements — qu'il entreprit en Nubie.

Des hypothèses assez fantaisistes ont été avancées, accordant à Tiyi une origine locale. Elles sont en bonne partie fondées sur la sublime statuette de la reine (aujourd'hui conservée au musée de Berlin) dont les traits ne sont pas sans rappeler ceux d'une Nubienne. Mais c'est essentiellement le matériau, un buis sombre autrefois peint, qui donne cette impression. des origines à la chute du sultanat Fung La famille de Tiyi est bien connue et ses deux parents, dont les momies ont été retrouvées dans la vallée des Rois, sont originaires d'Akhmîm, au nord de Thèbes. On sait qu'en l'an 5 Amenhotep III mena une campagne en Nubie, conduisant ses armées jusqu'au pays de Miou, sans doute près de Dangeil, en amont de la cinquième cataracte. Il est assez plausible que c'est lors de cette expédition qu'il choisit les deux sites de Soleb et de Sedeinga pour l'édification des deux temples. C'est peut-être aussi à cette époque que fut décidée l'installation à Soleb d'un délégué du vice-roi pour la province de Koush. Bien qu'isolé, le lieu n'était pas dépourvu de valeur stratégique puisqu'il se situait au débouché des pistes du désert Libyque et permettait à la fois de stopper d'éventuelles incursions des tribus de l'ouest et de réceptionner certains produits africains venus du Kordofan et du Darfour par cette route. Les fouilles du temple de Soleb sous la direction de Michela Schiff-Giorgini, de 1957 à 1977, ont montré que la construction s'était étalée sur 32 ans, avec une première phase se terminant la $17^{\mathrm{e}}$ année et un regain d'activité la $28^{\mathrm{e}}$ année. Le temple, initialement prévu comme sanctuaire d'Amon 


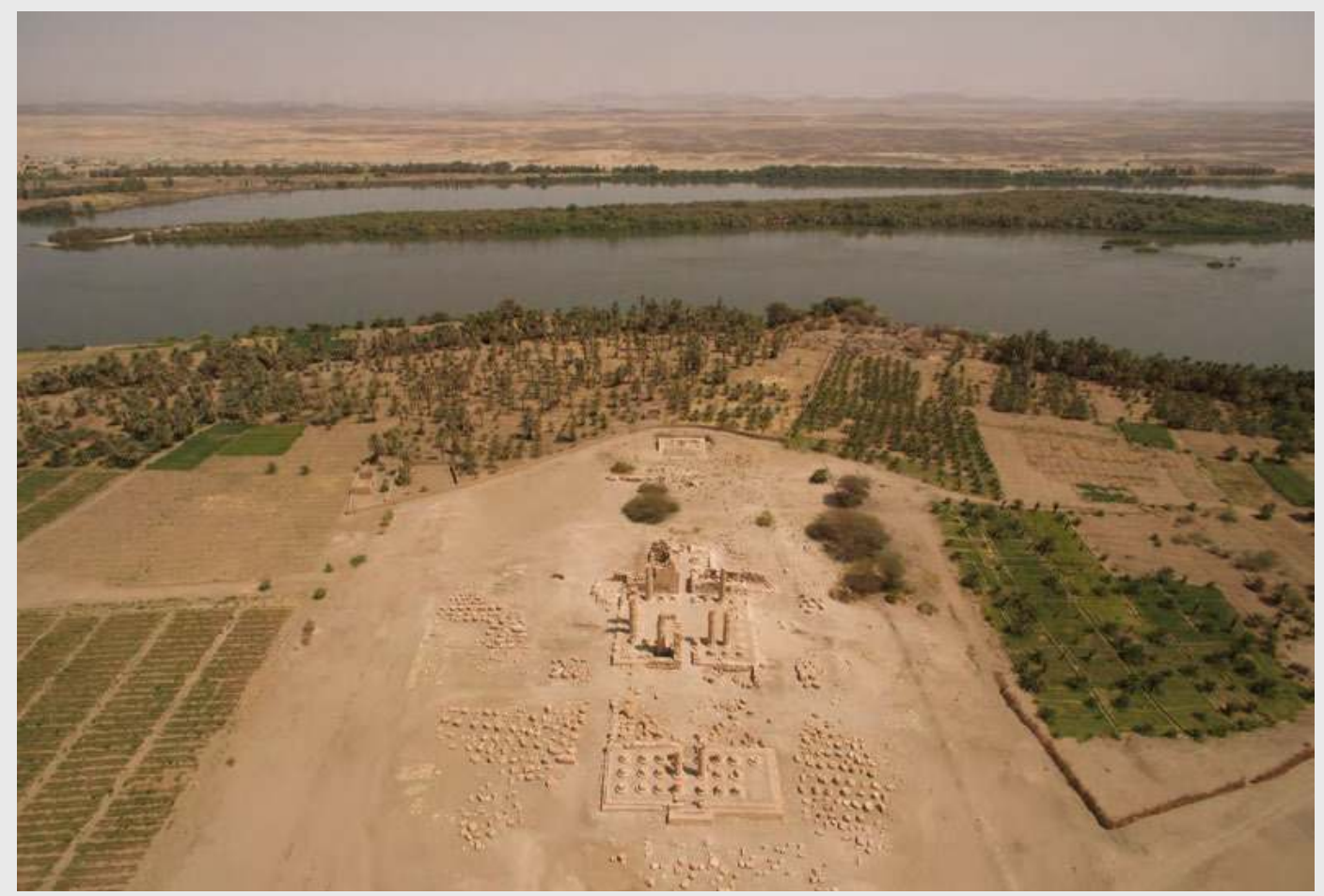

Le temple de Soleb, bâti par Amenhotep III.

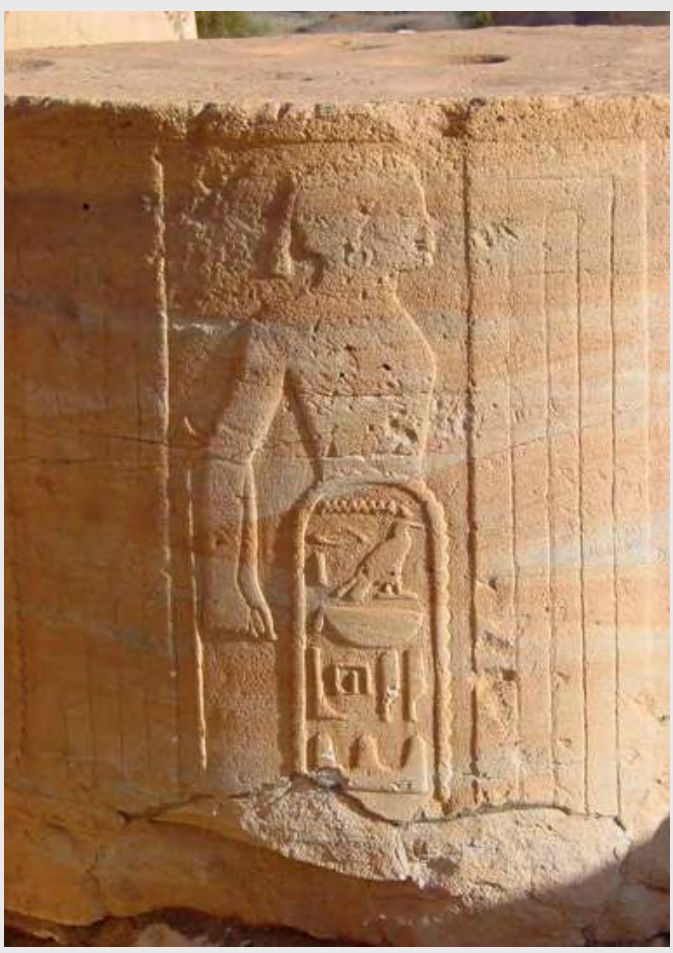

Salle hypostyle de Soleb, prisonnier nubien.

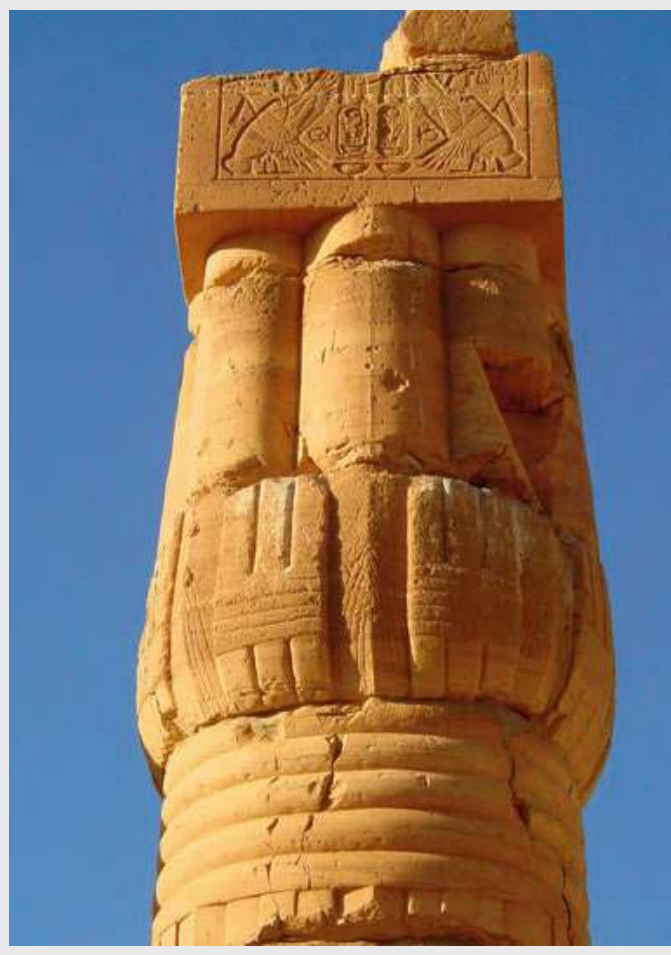

Colonne Nord, portant deux cartouches au nom de Nebmaâtrê. les fils

royaux

de Koush 


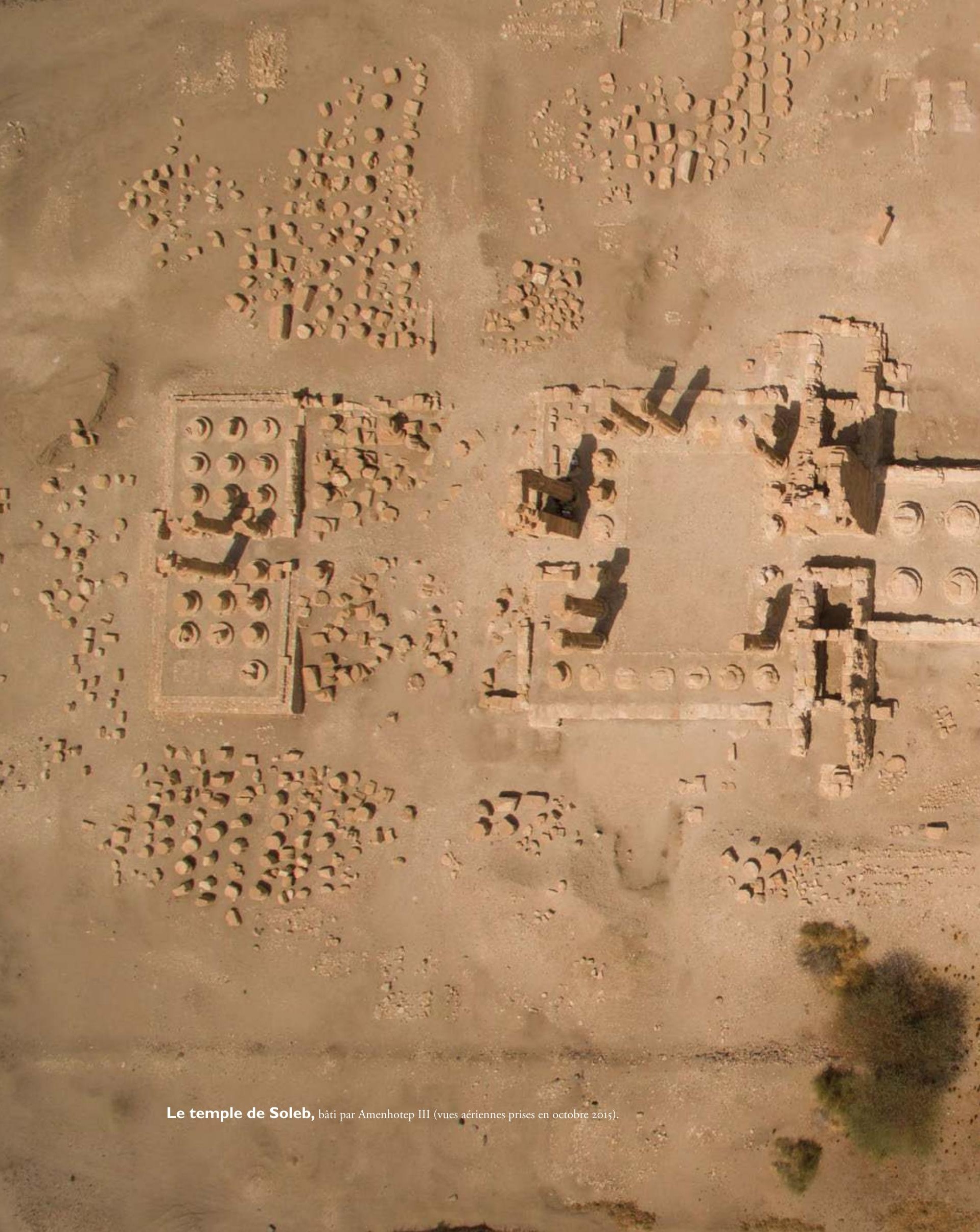




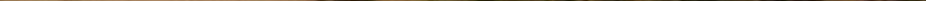




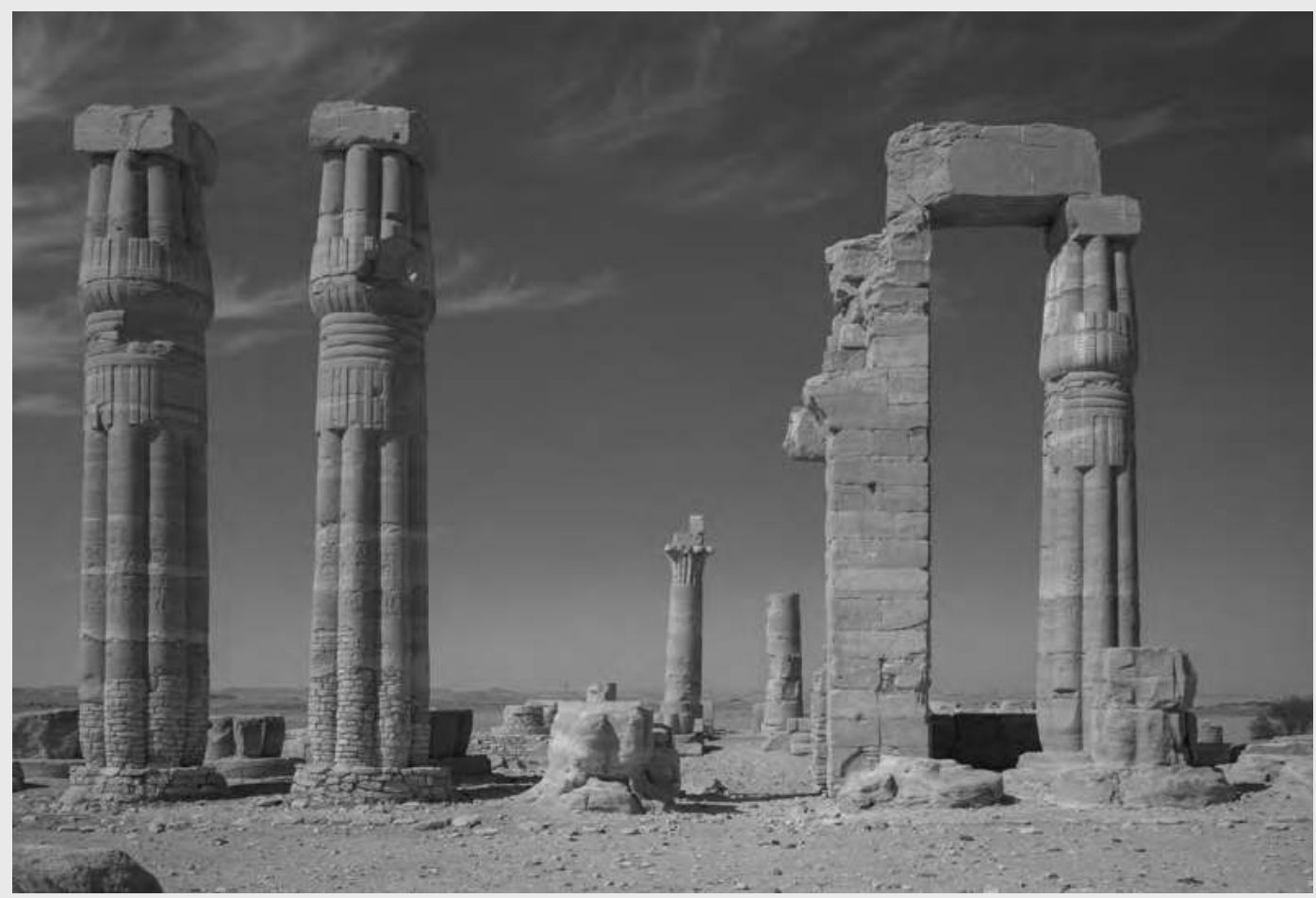

le Soudan

Soleb, la salle hypostyle.

\section{6}

des origines

à la chute

du sultanat

Fung

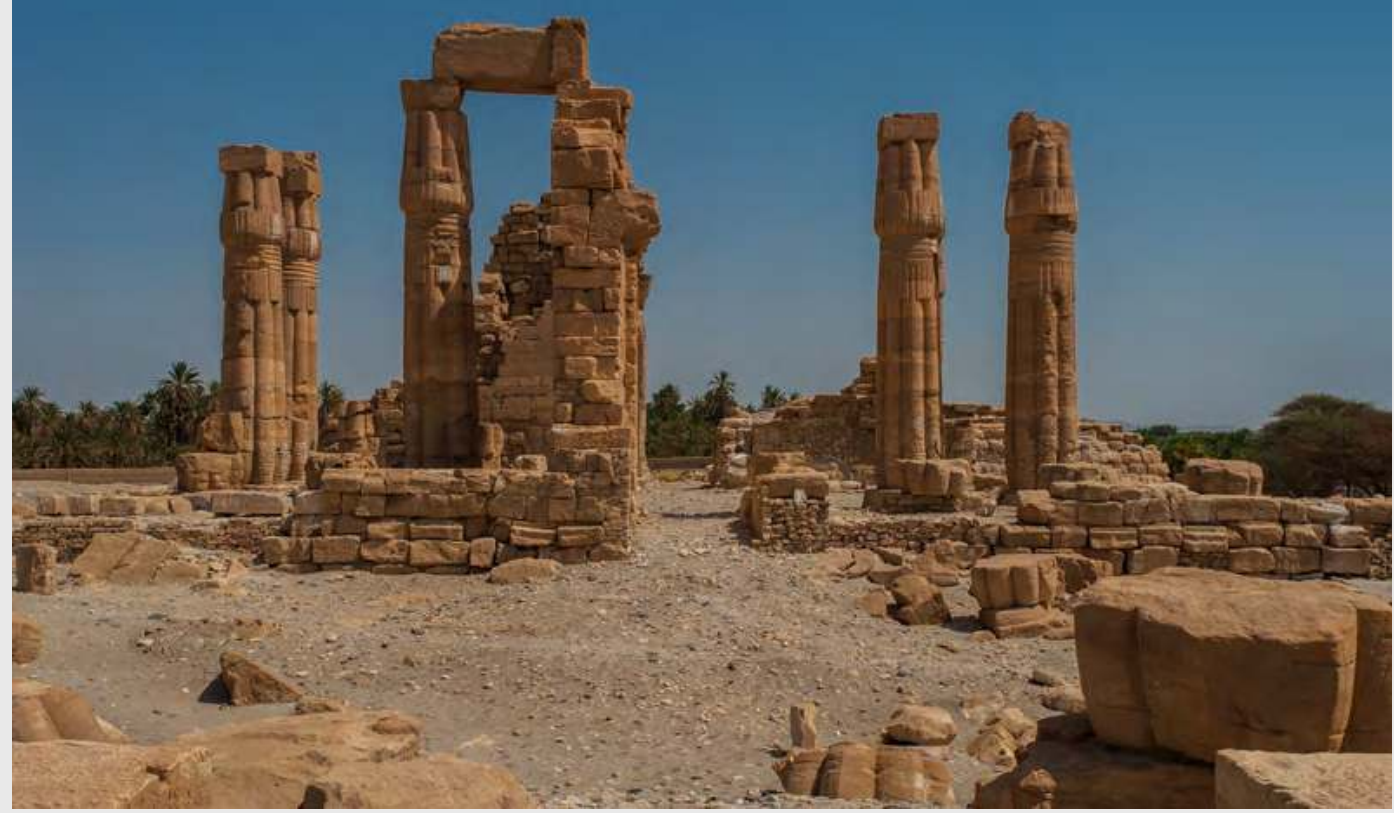

Soleb, le temple vu de l'est. 


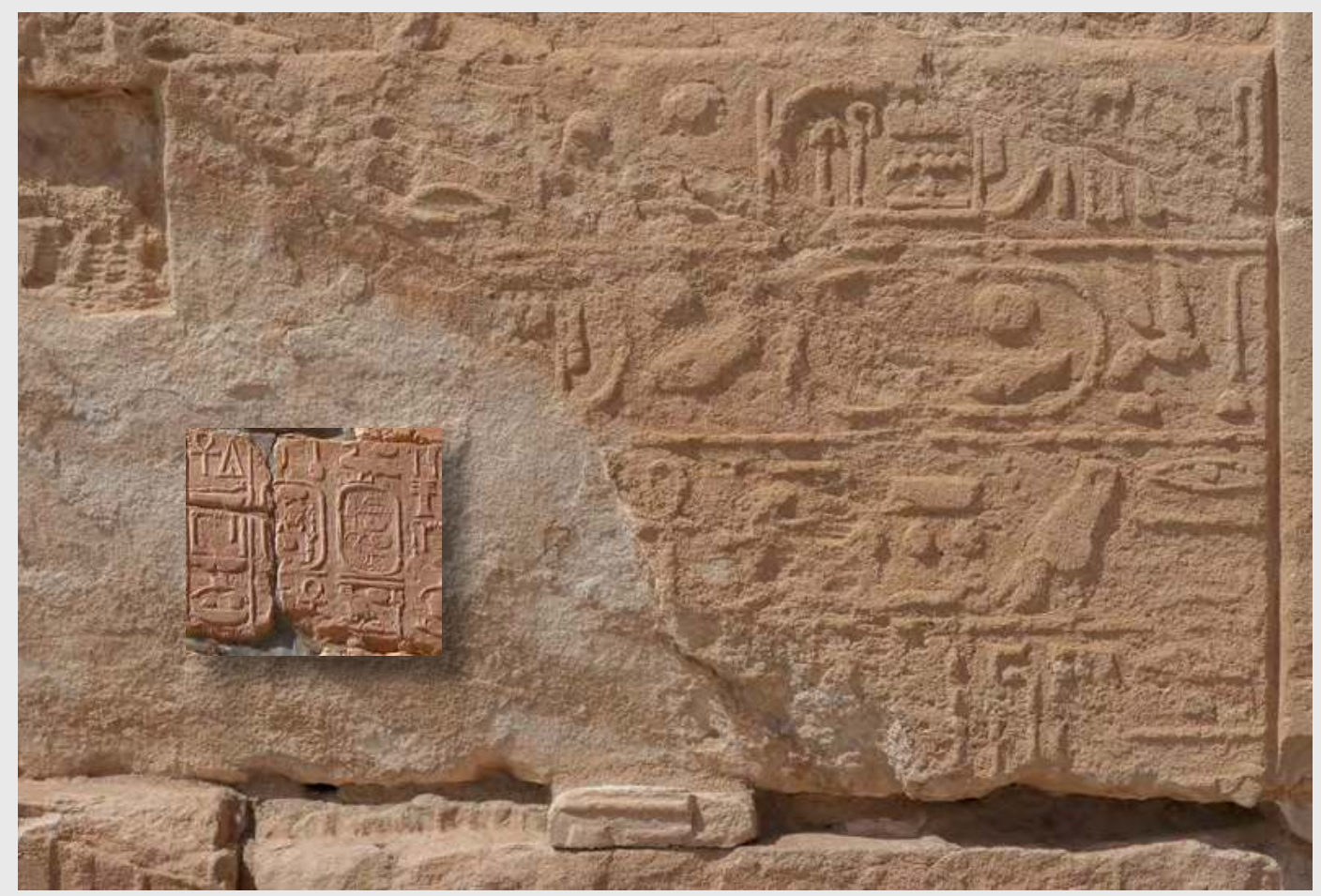

Soleb, cartouche martelé d'Amenhotep III et (en incrustation) inscription usurpée par Akhenaton.

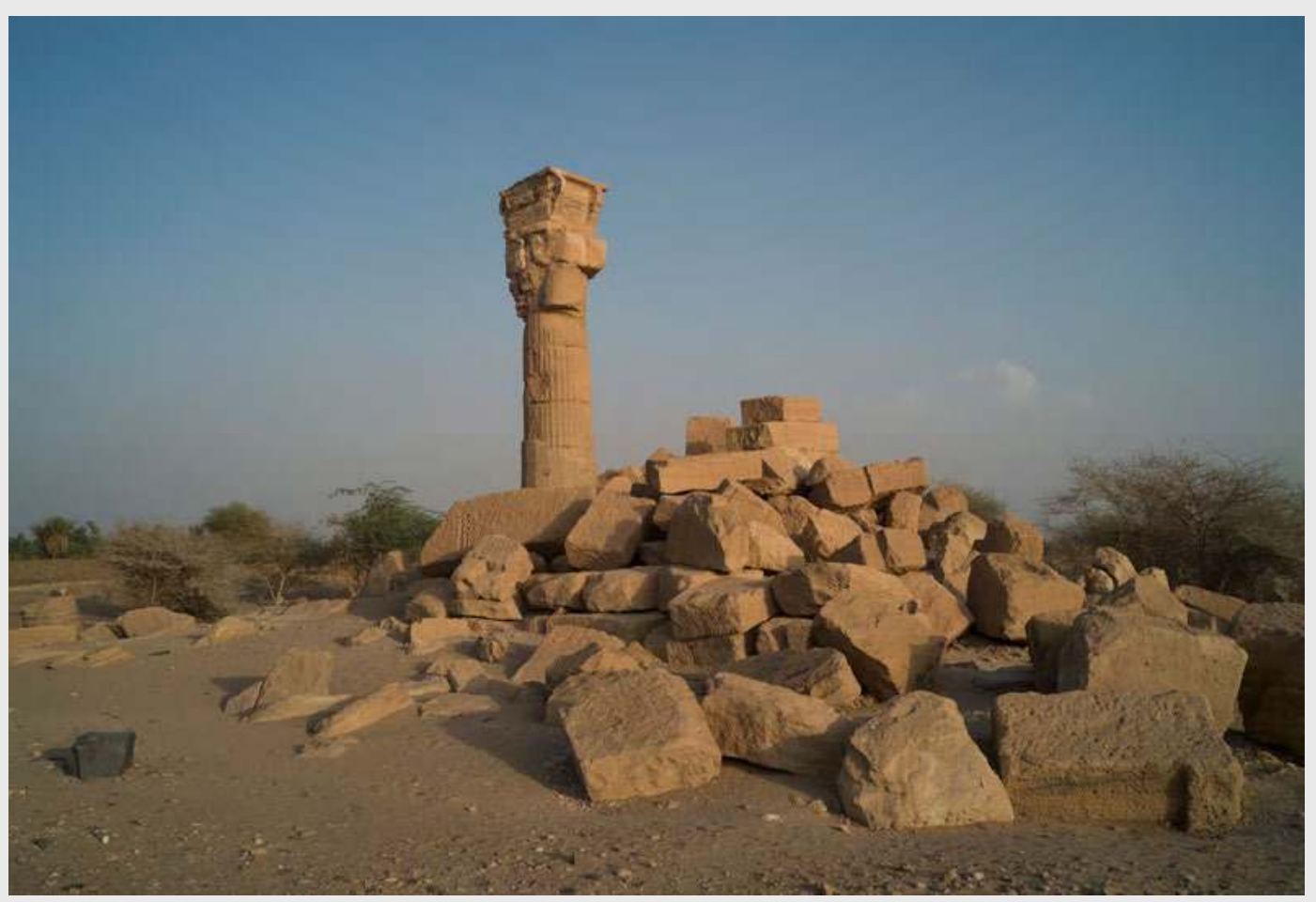

Sedeinga, octobre 2015, le temple de la reine Tiyi, grande épouse royale d'Amenhotep III, avant les travaux. 


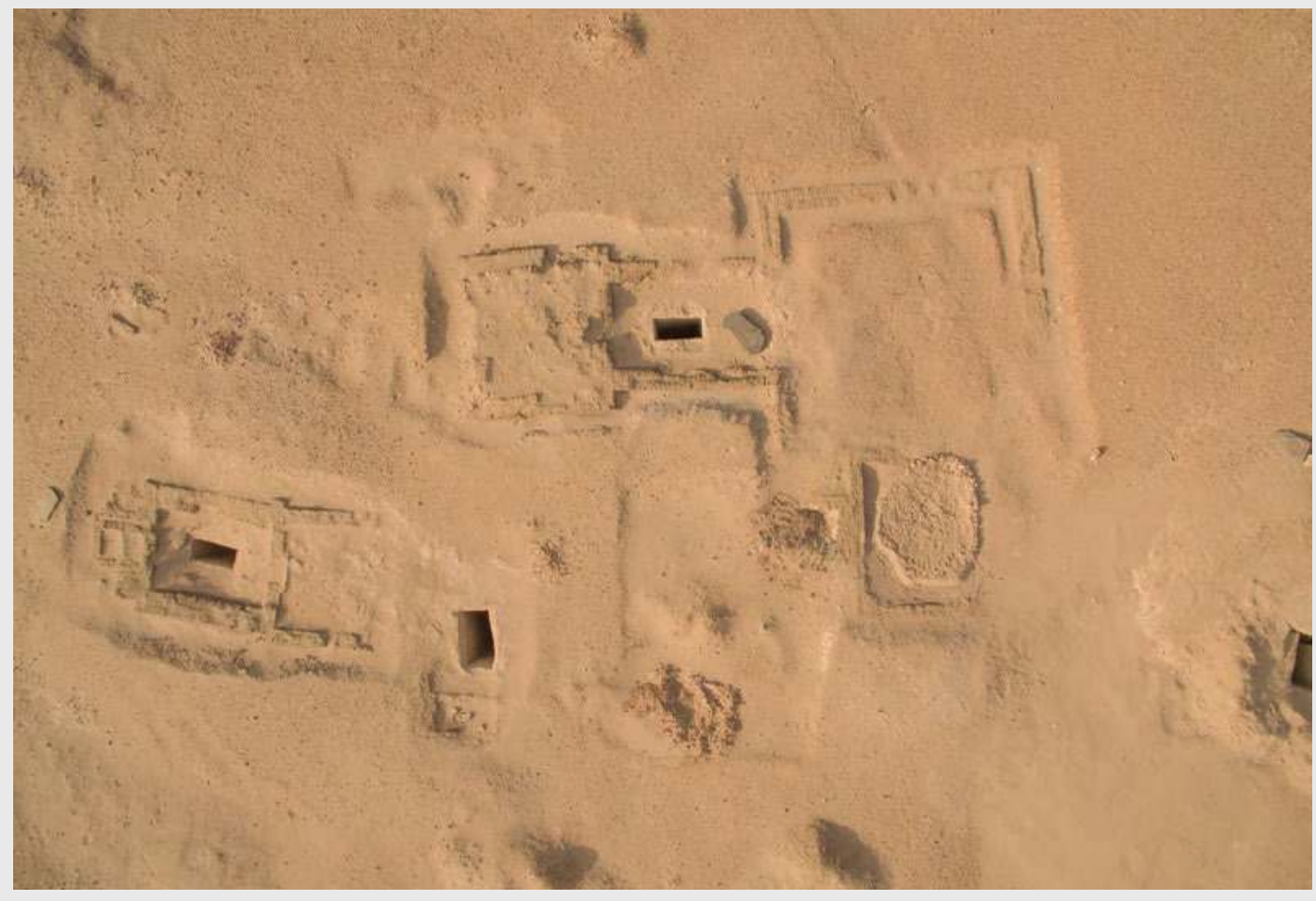

le Soudan

108

des origines

à la chute

du sultanat

Fung

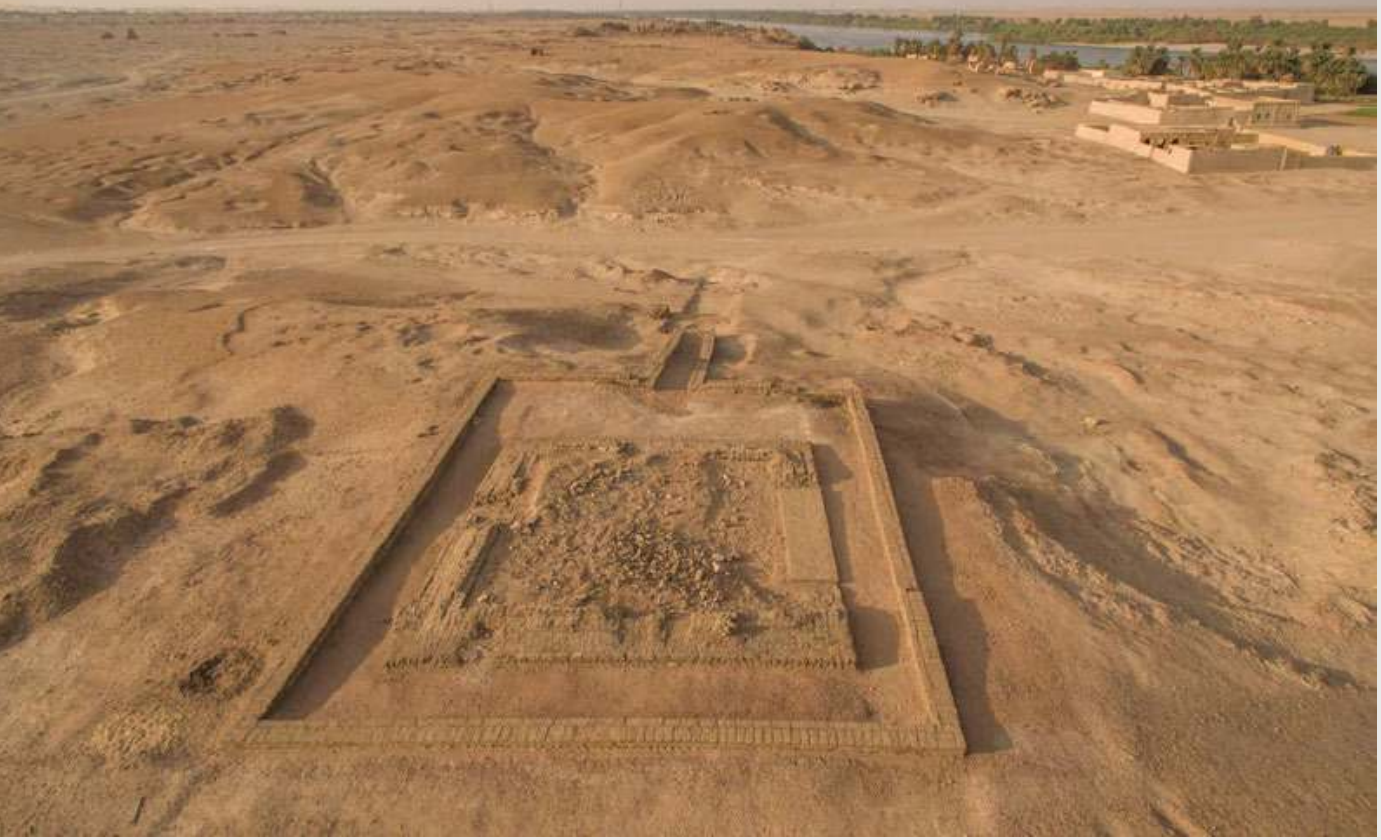

Saï, tombes de la XVIII dynastie.

Temple de Semna, inscription au nom de Thoutmosis III. 
et de Nebmaâtrê (on ne pouvait prévoir alors que le pharaon atteindrait sa trentième année de règne), aurait donc été achevé vers l'an 25, puis repris en l'an 33 pour commémorer après coup le premier jubilé du roi. L'édifice aurait donc été prêt pour le second jubilé célébré en l'an 34. Les aménagements ultimes dateraient en conséquence de l'an 37, la dernière année de règne d'Amenhotep III.

Parmi les hauts dignitaires entourant le roi dans les scènes du jubilé figure un homme-clef du pouvoir royal en Nubi: Mérymosé, "fils royal de Koush». À une date indéterminée, il a succédé à un viceroi nommé Amenhotep. Il semble avoir exercé cette fonction durant une longue période. Parmi les nombreuses inscriptions qu'il nous a laissées, une stèle de Semna nous renseigne sur l'organisation militaire de la colonie. Elle décrit une campagne contre le pays d'Ibehet, de localisation indécise. Il ne s'agit pas d'une opération importante qui aurait nécessité le renfort des troupes royales, voire l'intervention du souverain: le nombre d'ennemis tués s'élève à 312 et celui des prisonniers à 740 . La stèle détaille le recrutement de l'armée, entièrement composée de soldats issus des villages compris entre Qoubban et «le ménénou de Tery, soit une distance de 52 iterou $(544 \mathrm{~km})$ de navigation». Elle évoque le vice-roi procédant lui-même à la nomination de commandants parmi les recrues. Cette levée de troupes chez les ennemis d'hier, même si l'on devine qu'elle ne se fit pas sans contrainte, montre bien que la situation avait changé en Nubie depuis les campagnes sanglantes des débuts de la XVIII ${ }^{e}$ dynastie.

Sous le règne d'Akhenaton, puis celui de Toutânkhamon, alors

des origines

à la chute

du sultanat

Fung que l'Égypte était en difficulté sur les frontières asiatiques de son Empire, l'emprise sur la Nubie resta intacte. De nombreuses constructions furent entreprises. Dans le cadre de la révolution religieuse qu'il prôna durant les onze dernières années de son règne, Akhenaton modifia profondément les temples d'Amon à Kerma/Pnoubs et au Gébel Barkal afin d'en faire des sanctuaires dédiés à son dieu unique Aton, le disque solaire. Un nouveau ménénou fut érigé à Sésébi, $50 \mathrm{~km}$ au sud de Soleb: les trois colonnes qui subsistent du temple portent encore, profondément incisé dans le grès, le disque d'Aton, malgré l'usurpation des lieux sous Séthi ${ }^{\mathrm{I} r}$ au début de la XIX ${ }^{\mathrm{e}}$ dynastie. Sur le plan administratif, un «fils royal de Koush", Djéhoutimosé, est nommé. Une des preuves les plus éclatantes du contrôle royal sur la Nubie et du zèle de ce nouveau viceroi est l'aspect systématique des martelages dont le nom d'Amon a été victime. À Sedeinga, par exemple, deux stèles et un pan de chapelle du temple ont récemment été retrouvés réutilisés dans la nécropole méroïtique. Sur tous ces éléments, le nom et parfois la totalité de la figure d'Amon ont été martelés, puis restaurés (dans deux des monuments) sous 
le règne de Toutânkhamon. Sur les architraves, Akhenaton a semblablement fait effacer le nom de naissance de son père, Amenhotep ("Amon est satisfait»), et remplacer par son nom de couronnement (et de divinisation), Nebmaâtrê. À Soleb, c'est parfois le nom d'Akhenaton qui a été substitué à Amenhotep et, en quelques endroits, on a oublié de rétablir le cartouche originel sous les règnes suivants. À Saï, on a même poussé le zèle jusqu’à marteler dans une titulature royale le nom de Thèbes, la ville d'Amon. Peu après l'arrivée de Toutânkhamon au pouvoir vers 1336 av. J.-C., les cultes traditionnels revinrent en grâce. Malgré la brièveté de son règne personnel, ce roi n’est pas resté inactif en Nubie. Il fit notamment bâtir un temple à Kawa, au sud de Kerma, effaçant peut-être toute trace d'Akhenaton sur un premier sanctuaire dédié par son père au culte du disque solaire, puisque le nom égyptien du lieu était (et curieusement restera) Gematon, "celui qu’a trouvé Aton».

À la tête de la colonie fut nommé un nouveau «fils royal de Koush", appelé Houy, qui avait commencé sa carrière comme scribe du vice-roi Mérymosé sous Amenhotep III. Il est surtout connu pour les fresques superbes de son tombeau de la vallée des Nobles, près de Thèbes, qui dépeignent le tribut nubien apporté devant Toutânkhamon. Dans une des scènes, Houy est accueilli par les deux gouverneurs délégués qui le représentent de manière permanente en Nubie: celui de Wawat, établi désormais à Faras, près de la deuxième cataracte, et Aménémopé, gouverneur de Koush, qui résidait à Soleb et y sera inhumé.

Ce dernier offre un bon exemple de la façon dont les Égyptiens intégrèrent les élites locales dans l'administration de la Nubie. Originaire de Miam, une des principautés de Basse-Nubie laissée en place par les conquérants autour d'Aniba, il reçut une éducation égyptienne et commença sa carrière, à l'instar de Houy, comme scribe auprès du vice-roi Mérymosé sous le règne d'Amenhotep III. Il fut ensuite intendant des travaux du vice-roi Djéhotimosé sous Akhenaton, puis termina sous Toutânkhamon comme gouverneur de Koush, représentant du vice-roi Houy dans cette province méridionale. Un autre membre de sa famille, Heqanéfer, fut élevé à la cour thébaine comme «enfant du kap» (cette école où l'on intégrait des jeunes princes étrangers), puis fut nommé prince de Miam. Son tombeau édifié près de Tochka d'Égypte est celui d'un haut fonctionnaire égyptien, dont il arbore tant le costume que l'apparence physique.

Pourtant, dans les fresques de la tombe de Houy, il figure, auprès des autres grands de Wawat, vêtu à la nubienne d'une peau de panthère, une plume d'autruche fixée dans la coiffure et sous des traits incontestablement nubiens. Égyptien chez les Nubiens, Nubien chez les Égyptiens, Heqanéfer est caractéristique de cette élite acculturée qui préfigure l'émergence de la dynastie de Napata. 


\section{La fin de la domination égyptienne}

Sous la XIX ${ }^{\mathrm{e}}$ dynastie, la colonie nubienne continua à fonctionner selon ces principes. Le siège des deux gouvernorats était désormais fixé à Faras, puis à Akcha pour Wawat et à Amara pour la province de Koush. Le tribut annuel rentrait régulièrement et l'on en trouve une description picturale très détaillée dans les reliefs du temple de Beit el-Wali, en Basse-Nubie, commencé sous Séthi I ${ }^{e r}$ (env. 1294-1279) et achevé au début du règne de Ramsès II (env. 1279-1212). Rien n'y manque: bœufs, animaux sauvages vivants (dont des singes, un ibex, une gazelle, un girafon, un guépard et un lion), peaux de panthère, plumes et oufs d'autruche, madriers d'ébène, défenses d'éléphant, or, huiles précieuses, produits manufacturés divers comme les arcs, les éventails ou les chaises de luxe. Sous Ramsès II, d'importants travaux architecturaux marquèrent durablement le paysage nubien. Successivement, les temples de Beit el-Wali, Akcha, Amara-Ouest, Derr, Ouadi es-Seboua et Gerf Hussein furent construits ou achevés durant son règne. La plupart d'entre eux sont situés en Basse-Nubie et ponctuent le grand tour de Nubie égyptienne qu'effectuent les touristes qui embarquent à Assouan. Aucun d'entre eux, cependant, n'a conservé sa localisation d'origine, puisqu'ils étaient menacés par le lac de retenue du haut barrage d'Assouan et ont été déplacés entre 1963 et 1964 dans le cadre d'une collaboration internationale dirigée par l'Unesco. Mais le joyau suprême de ce diadème posé sur le front de la Basse-Nubie est incontestablement Abou Simbel. Taillés dans le roc en l'espace de vingt ans, ses deux

des origines

à la chute

du sultanat

Fung temples sont consacrés à Ramsès II divinisé et à sa grande épouse royale Néfertari, assimilée quant à elle à la déesse Hathor. Comme pour bien des monuments érigés par ce souverain, il y a une volonté d'imiter son lointain prédécesseur Amenhotep III qui, le premier, avait fait construire un temple (non funéraire) à sa propre divinité à Soleb et un autre à Sedeinga dédié à la reine Tiyi, déjà associée à Hathor. Mais la solution architecturale retenue par Ramsès, le spéos (temple rupestre), a permis une meilleure conservation de ces sanctuaires que ceux érigés par Amenhotep III.

Le choix de la Basse-Nubie pour ce grand projet est probablement lié à des raisons logistiques. La construction d'Abou Simbel fut supervisée par le vice-roi de Nubie Iouny, déjà en poste sous Séthi I ${ }^{\text {er }}$, mais surtout par Heqanakht, qui dès l'an 3 du règne, avait succédé à Iouny et restera à la tête de la colonie pendant une vingtaine d'années. L'existence de plusieurs temples en construction à la même époque impliquait des allers et retours fréquents non seulement pour le vice-roi mais aussi pour les spécialistes qui intervenaient sur tous les chantiers royaux d'Égypte, particulièrement nombreux sous le règne de ce pharaon bâtisseur. La relative proximité 
de la Basse-Nubie permettait d'acheminer plus facilement de la main-d'œuvre depuis l'Égypte, car le recrutement local ne suffisait pas. On sait en effet qu'en l'an 44 du règne le vice-roi Sétaou lança des expéditions contre les oasis du désert occidental et contre les pays d'Irem et d'Akita, deux régions situées sur les marches de Koush, pour se procurer des esclaves destinés à la construction du temple de Ouadi es-Seboua. Si le gros de l'activité architecturale fut concentré sur la Basse-Nubie, les régions situées plus au sud ne furent pas délaissées. La ville d'Amara-Ouest fut fondée à cette époque pour remplacer Soleb comme siège du gouverneur de Koush et fut dotée d'un temple dédié à Ramsès II divinisé. Des aménagements sont attestés à Sésébi, Kerma/Pnoubs, à Kawa et dans le temple d'Amon du Gébel Barkal sous les règnes de Séthi Ier et de Ramsès II.

Sous la seconde moitié de la XIX dynastie et la plus grande partie de la XXe dynastie (env. 1188-1069), nos sources sur l'histoire de la Nubie sont beaucoup moins nombreuses. On a supposé que les Égyptiens, confrontés à des difficultés économiques et à une situation militaire délicate en Basse-Égypte, liée aux invasions des Peuples de la Mer et à des incursions libyennes, s'étaient retirés au nord de la province de Koush. Toutefois, il s'agit sans doute en grande partie d'une illusion d'optique due à la pauvreté des témoignages archéologiques et textuels. Sous Ramsès IX (env. 1125-1107), en effet, un administrateur au service du vice-roi est attesté par les fragments de sa statue au Gébel Barkal. Il est vrai qu’aucun chantier d'ampleur comme ceux des dynasties antérieures n'est entrepris. Mais l'administration et l'entretien des multiples complexes religieux que les pharaons des deux dynasties précédentes avaient fondés sur l'ensemble de la colonie demandaient un effort jugé suffisant.

C'est de cette Nubie pacifiée que viendra paradoxalement l'un des coups principaux qui aboutira à l'effondrement de la XXe dynastie. Vers l'an $9 \mathrm{du}$ long règne du dernier de ses souverains, Ramsès XI (vers 1 098-1 069), un nouveau "fils royal de Koush», Panéhésy, est nommé. Malgré son nom qui signifie «Le Noir» et qui n'est peut-être qu'un sobriquet, il n'est pas sûr qu'il ait eu des origines méridionales. En l'an 17, la dégradation du pouvoir central et les crises économiques qui s'ensuivirent engendrèrent des troubles importants dans la région de Thèbes, au point que Ramsès XI, dont le pouvoir était chancelant, chargea Panéhésy de descendre le Nil jusqu'en Haute-Égypte avec les contingents nubiens pour y faire régner l'ordre. Une fois sur place, loin de ramener le calme, le vice-roi et ses troupes se mirent à piller les temples et les nécropoles royales. Le pharaon le somma alors de quitter Thèbes, mais Panéhésy, conscient de la faiblesse du dernier des Ramsès, entra en révolte. Le général Piânkh fut alors envoyé contre lui et nommé vice-roi de Nubie en lieu et place du rebelle. 


\section{4}

des origines

à la chute

du sultanat

Fung

Toutefois, cette période coïncida avec un découpage du pouvoir entre deux hommes forts, Smendès en Basse-Égypte et Hérihor, grand-prêtre d'Amon, en Haute-Égypte, tandis que le pharaon légitime, Ramsès XI, n'exerçait plus qu'une autorité fantoche. Piânkh repoussa effectivement Panéhésy en Nubie, mais il ne fit guère plus d'efforts, semble-t-il, pour regagner la colonie dont il était devenu vice-roi officiel. Panéhésy y établit une principauté indépendante, tandis que Piânkh succéda à Hérihor comme grand-prêtre d'Amon, prenant ainsi le contrôle de la Haute et Moyenne-Égypte. De son côté, Smendès, maître de la Basse-Égypte, se proclama pharaon à la mort de Ramsès XI, inaugurant ainsi la XXI ${ }^{\mathrm{e}}$ dynastie.

Panéhésy gouverna sa principauté indépendante de BasseNubie sans être autrement inquiété jusqu’à sa mort et fut inhumé à Miam (moderne Aniba). Peu après, les rois de la XXI ${ }^{e}$ dynastie reprirent le contrôle de la Nubie, bien qu'il soit difficile de préciser jusqu'où s'étendait leur pouvoir. Semblablement, on ignore, faute de sources épigraphiques, la plupart des vice-rois qui y furent nommés. Le premier dont le nom nous soit parvenu, sous le règne de Pinedjem II (vers 990-969), est en fait sa propre épouse, Neskhons, «fille royale de Koush». Trois autres vice-rois postérieurs sont connus, le dernier étant le gendre du roi Takelot III (754734) de la XXIII e dynastie, Pamiou. Il est cependant difficile de savoir s'ils exerçaient cette fonction sur le terrain ou s'il s'agissait d'un titre purement honorifique. Aucun d'entre eux n'est ainsi attesté par une inscription en Nubie. On sait, grâce aux fouilles récentes des cimetières d'Hillat el-Arab, près du Gébel Barkal, et de ceux d'Amara et de Tombos, que le pays a continué d'entretenir des liens étroits avec l'Égypte. Les produits africains arrivent toujours à la cour royale, d'où ils sont parfois expédiés en Assyrie en guise de cadeaux diplomatiques. Mais sont-ils acquis par tribut ou au terme d'échanges commerciaux? Après Pamiou, vers 750 av. J.-C., le titre disparaît: à cette époque, en effet, la Nubie est entièrement entre les mains d'une nouvelle lignée de rois koushites, qui ne tarderont pas à envahir l'ensemble de l'Égypte et à y établir la XXVe dynastie 